\title{
Tidal Effects on Circulation in and near the East China Sea
}

\author{
Hung-Jen Lee ${ }^{1, *}$, Shenn-Yu Chao ${ }^{2}$, Kon-Kee Liu ${ }^{3}$, Shih-Jen Huang ${ }^{1}$, and Gwo-Ching Gong ${ }^{4,5}$ \\ ${ }^{1}$ Department of Marine Environmental Informatics, National Taiwan Ocean University, Keelung, Taiwan \\ ${ }^{2}$ Horn Point Laboratory, University of Maryland Center for Environmental Science, Cambridge, USA \\ ${ }^{3}$ Institute of Hydrological and Oceanic Sciences, National Central University, Jhongli, Taiwan \\ ${ }^{4}$ Institute of Marine Environmental Chemistry and Ecology, National Ocean Taiwan University, Keelung, Taiwan \\ ${ }^{5}$ Taiwan Ocean Research Institute, Kaohsiung, Taiwan
}

Received 24 July 2013, accepted 8 October 2013

\begin{abstract}
We incorporate tidal currents into a previously validated, three-dimensional, subtidal circulation model to assess tidal effects on the circulation in and around the East China Sea. Of particular interest is the tide-enhanced Changjiang plume dispersal and circulation in the southern East China Sea. The modeling results show that without tides, the Changjiang plume in summer presents itself as a stagnant, expansive pool in regions bordering the northern East China Sea and Yellow Sea, too far north and too accumulating relative to observations. The winter plume dispersal pushed by the north-northeast monsoon follows the China coastline southeastward as a coastal current that matches more closely with observations with or without tides. Incorporating the effect of tides brings the model closer to observation, especially in summer. During summer the Taiwan Warm Current shifts to lower latitudes, enhances upwelling off southeast China and induces a southward tidal residual coastal flow off southeast China. Tides also induce the observed seaward detachment of the summer plume. In winter, the prevailing north-northeast monsoon suppresses the Taiwan Warm Current to the minimum. However, if the winter monsoon is weakened for a few weeks, the Taiwan Warm Current reappears and these three mechanisms begin to operate as in summer. CTD surveys and satellite observations south of the Changjiang River estuary contribute to a better understanding of the tidal effects on regional ocean currents.
\end{abstract}

Key words: Changjiang plume, Taiwan Warm Current, Tidal residual coastal flow

Citation: Lee, H. J., S. Y. Chao, K. K. Liu, S. J. Huang, and G. C. Gong, 2014: Tidal effects on circulation in and near the East China Sea. Terr. Atmos. Ocean. Sci., 25, 233-254, doi: 10.3319/TAO.2013.10.08.01(Oc)

\section{INTRODUCTION}

Off shore of eastern China, the three-sea (East China Sea, Yellow Sea, and Bohai) system over the continental shelf borders the deep western Pacific Ocean (Fig. 1a). The East China Sea is sufficiently open to the western Pacific Ocean. Farther north, the Yellow Sea and Bohai become increasingly landlocked due to the presence of Korean peninsula and Japanese land masses to the east. Both tidal and subtidal circulations are sufficiently strong in the three-sea system. The tidal circulation is mostly driven by the westward propagation of barotropic, astronomical tides in the Pacific Ocean. Shoaling bottom over the shelf amplifies tidal currents. Some tidal energy propagates northward into the Yellow Sea and Bohai in regions north of the Changji-

\footnotetext{
* Corresponding author

E-mail:lecgyver@mail.ntou.edu.tw
}

ang mouth. South of the Changjiang mouth, tides propagate southward as coastal Kelvin waves after impinging on the Chinese coast (Jan et al. 2002). The subtidal circulation arises from multiple sources, each having a varying degree of seasonal variation. The bordering Kuroshio over the continental slope, the East Asian monsoon, river runoff (most notably from Changjiang or Yangtze River) and the northward Taiwan Warm Current from the Taiwan Strait all come into play. Among all external forces, the East Asia monsoon (Figs. $1 \mathrm{~b}$ and c) stands out as the dominant force driving the seasonal circulation of the East China Sea.

Previous numerical models of ocean circulation in this region have varied from subtidal (e.g., Lee and Chao 2003) to tidal (e.g., Lee and Beardsley 1999; Lefevre et al. 2000; $\mathrm{Hu}$ et al. 2010). A few intermediate models ( $\mathrm{Li}$ and Rong 2012; Rong and Li 2012) examined interactions between 
Changjiang plumes and tides in the absence of mean circulation. Moving one step further, Moon et al. (2010) and Wu et al. (2011) included the mean shelf circulation in addition to river and tidal forcing, focusing on how tides induce the offshore detachment of Changjiang plume in summer. By including tides, the modeled summer intrusion of Changjiang plume into the Yellow Sea is much reduced, bringing the modeled plume dispersal closer to reality (Wu et al. 2011).

Theoretically speaking, tides generally enhance horizontal and vertical mixing, which could in turn alter the subtidal circulation. The consequences can be seen in the intertidal range. On the other hand, subtidal circulation could also change subtle characteristics of tides through mechanisms such as internal tide generation. The consequence is mostly intra-tidal and should be analyzed as such, which requires a different methodology. In this work, we focus on the conversion from tidal to subtidal currents primarily in the region from the Changjiang mouth to the southern end of the East China Sea.

The Changjiang is a major supplier of freshwater, sediments and river-borne nutrients to the East China Sea (Liu et al. 2008). The subsequent dispersal is under the influence of monsoon winds, the encroaching Taiwan Warm Current, the Kuroshio intrusion and, last but not the least, tidal currents. (a)

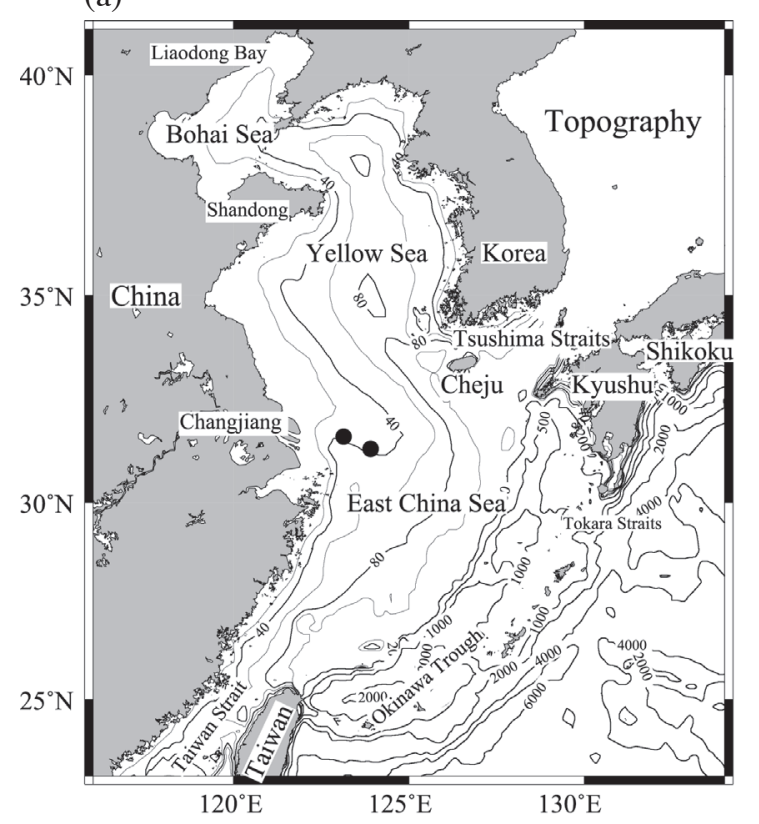

(c)

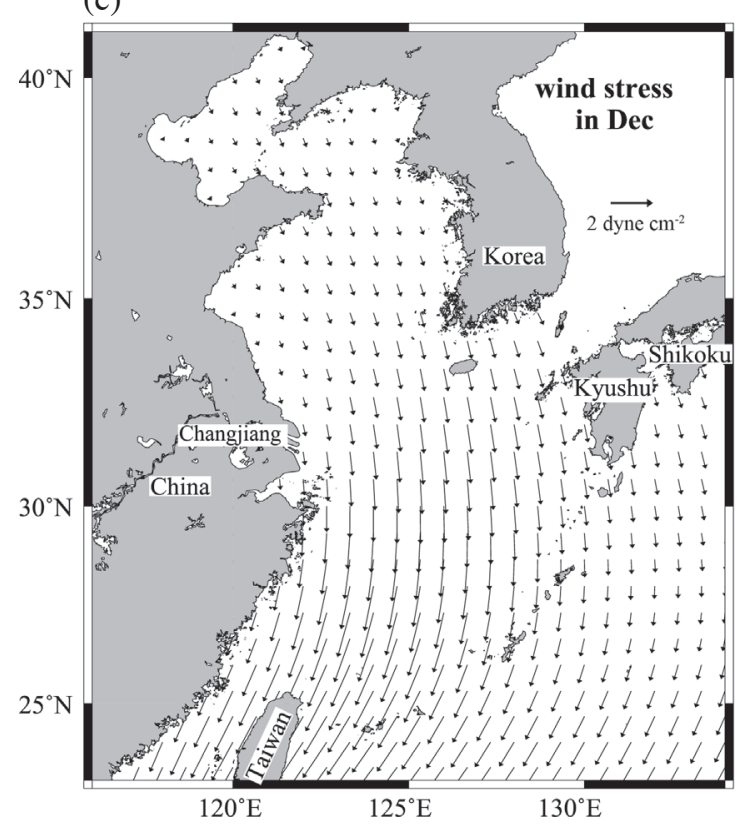

(b)

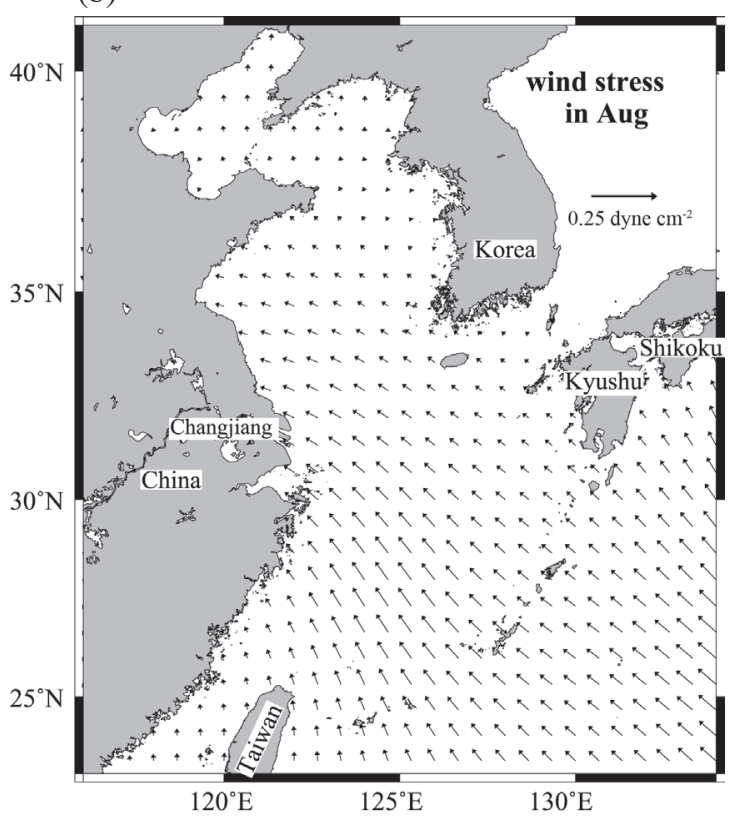

Fig. 1. Model topography in meters (a), and monthly climatology wind stress in August (b) and December (c). Large dots A and B in (a) indicate the summer CTD stations. 
Shoaling tidal currents and their spring-neap variations (Lefevre et al. 2000) regulate the freshwater discharge and subsequent mixing with surrounding seawater. In light of the importance of tidal currents, in this study we focused on the tidal to subtidal circulation and have examined other parts of the three-sea system.

\section{MODEL FORMULATION}

The model solves for 3-D temperature, salinity and momentum equations under hydrostatic and Boussinesq approximations. Leaving conventional momentum and continuity equations aside, conservation equations for temperature $(T)$ and salinity $(S)$ are

$$
\partial_{t} T+v \cdot \nabla T+w \partial_{z} T=\theta+r\left(T^{*}-T\right)
$$

$\partial_{t} S+v \cdot \nabla S+w \partial_{z} S=\delta+r\left(S^{*}-S\right)$

where $\theta$ and $\delta$ are mixing terms, $v$ is the horizontal velocity vector, $\nabla$ is the horizontal gradient operator and $w$ is the vertical velocity. Following Sarmiento and Bryan (1982), we nudge temperature and salinity slowly toward their respective climatologic values, $T^{*}$ and $S^{*}$ (Levitus and Boyer 1994) only above and below thermocline. This measure allows the thermocline to move freely. The restoration rate $(r)$ for temperature and salinity is therefore depth dependent: $1 /(50$ days) between 0 and $50 \mathrm{~m}, 0$ between 50 and $870 \mathrm{~m}$, and $1 /(250$ days $)$ below $870 \mathrm{~m}$.

The calculation will become diagnostic if the restoration rate is too large but prognostic if it is too small. Since climatologic $T^{*}$ and $S^{*}$ at 1-degree resolution are too coarse to resolve the Changjiang plume, our choice of $r$ is within the range to allow for considerable deviation. The upstream boundary is 5 grids up the Changjiang mouth. Entering the East China Sea, the volumetric flux from the upstream boundary of the Changjiang is fixed at the monthly climatology value. As the water level rises and falls with tides and winds, the instantaneous inflow from Changjiang must be adjusted accordingly to maintain the prescribed volumetric flux, which enhances the computational stability.

The study area extends from $23^{\circ}$ to $41^{\circ} \mathrm{N}$ and from $118^{\circ}$ to $134^{\circ} \mathrm{E}$ with a horizontal resolution of $1 / 6^{\circ}$ $(\Delta x=\Delta y \approx 18.5 \mathrm{~km})$. The time step is $8 \mathrm{~s}$ for the barotropic mode and $400 \mathrm{~s}$ for the baroclinic mode. Both are small enough to resolve the dominant $\mathrm{M}_{2}$ tidal period (12.42 hours). The Kelvin number (K) for the Changjiang, the ratio of estuary mouth width (W) to the baroclinic Rossby radius $\left(\mathrm{R}_{\mathrm{i}}\right)$, is larger than one. The Rossby radius, $\mathrm{R}_{\mathrm{i}}=\mathrm{c} / f$, where $\mathrm{c}$ is the first mode internal wave speed, and the Coriolis parameter $(f)$ of approximately $7.7 \times 10^{-5} \mathrm{~s}^{-1}$, can be estimated from two summer CTD stations (A and B) off the Changjiang mouth as shown in Fig. 1a. The internal wave speed is estimated from $\mathrm{c} \approx \sqrt{g H \delta \rho / \rho}$; where $H$ is the mean water depth, and $\delta \rho$ is the density difference between the surface and bottom layers and $g$ is the gravitational constant. The internal wave speed (c) is about $1.82 \mathrm{~m} \mathrm{~s}^{-1}$ at station A and $1.75 \mathrm{~m} \mathrm{~s}^{-1}$ at station $\mathrm{B}$. The corresponding Rossby radii are about 23.6 and $23.4 \mathrm{~km}$ at stations $\mathrm{A}$ and $\mathrm{B}$, respectively. The Changjiang mouth is about $38.4 \mathrm{~km}$ wide, leading to a Kelvin number $(\mathrm{K})$ of about 1.63 at station $\mathrm{A}$ and 1.64 at station B. In other words, the effect of earth rotation is important for the Changjiang plume.

Beside sea level variations, the top upper layer is $5 \mathrm{~m}$ thick on average and the thickness of each layer is $85 \%$ of that immediately below. With 33 levels in the vertical, the maximum basin depth reaches $6018 \mathrm{~m}$. The horizontal mixing coefficient is $5000 \mathrm{~m}^{2} \mathrm{~s}^{-1}$ for momentum, $50 \mathrm{~m}^{2} \mathrm{~s}^{-1}$ for temperature and salinity. Coefficients of vertical viscosity and diffusivity are calculated from the Richardson number according to the formulation of Pacanowski and Philander (1981). All solid boundaries are impermeable, impenetrable and no-slip except the bottom, where we impose quadratic bottom friction with a drag coefficient of 0.0015 , which seems optimal for the development of semidiurnal tides (Guo and Yanagi 1998).

Monthly climatology wind (NCEP data, averaged from 1979 to 2006) is used as default values to drive the subtidal circulation. Figures $1 \mathrm{~b}$ and $\mathrm{c}$ show, respectively, the wind stress in August and December. On one occasion, we also use the monthly climatology wind of Hellerman and Rosenstein (1983) as a diagnostic tool to illustrate the sensitivity of Changiiang plume detachment to wind strength. Leaving tidal currents aside, Table 1 lists monthly mean inflows and outflows through open ocean boundaries of the model domain. For the Changjiang discharge, Table 2 lists the monthly mean inflow, temperature and salinity as compiled by the Global Runoff Data Center of the Federal Institute of Hydrology in Germany.

We also impose tidal elevations and currents on open boundaries using the result from a 2-D barotropic tide model with $1 / 12^{\circ}$ resolution (Hu et al. 2010). Their tide-induced sea level contains 6 tidal constituents $\left(\mathrm{P}_{1}, \mathrm{O}_{1}, \mathrm{~K}_{1}, \mathrm{~N}_{2}, \mathrm{M}_{2}\right.$, and $\mathrm{S}_{2}$ ). Using parameters extracted from their model, our tide-induced sea level is

$S=\sum_{n=1}^{6} f_{n} S_{n} \cos \left(\omega_{n} t+\theta_{n}\right)$

where $f_{n}$ is the nodal factor, $S_{n}$ is the sea level, $\omega_{n}$ is the frequency and $\theta_{n}$ is the phase lag of each tidal constituent. Our model year is climatologic in the sense that, in addition to using monthly climatologic forcing, each month is 30 days long. To simulate tides in one particular year, time-explicit, intra-monthly forcing can be used to drive subtidal circulation and add the proper initialization phase (phase angle of equilibrium tides and nodal angle) to Eq. (3). However, 
Table 1. Monthly transport (in Sv) through open ocean boundaries. Positive and negative transport correspond to inflow and outflow, respectively.

\begin{tabular}{ccccccccccccc}
\hline Month & January & February & March & April & May & June & July & August & September & October & November & December \\
\hline Taiwan Strait & 0.5 & 0.5 & 1.5 & 1.5 & 2.2 & 2.3 & 2.3 & 2.4 & 2.4 & 1.5 & 0.5 & 0.5 \\
Kuroshio Inflow & 22.0 & 22.0 & 22.5 & 23.0 & 24.0 & 23.5 & 23.5 & 28.0 & 28.0 & 22.0 & 21.0 & 22.0 \\
Kuroshio Outflow & -20.24 & -20.62 & -22.27 & -22.63 & -23.96 & -23.04 & -22.53 & -26.74 & -26.59 & -19.83 & -18.2 & -19.72 \\
Tsushima Straits & -2.27 & -1.89 & -1.75 & -1.89 & -2.28 & -2.80 & -3.32 & -3.71 & -3.85 & -3.71 & -3.33 & -2.80 \\
\hline
\end{tabular}

Table 2. Monthly discharge (in Sv), temperature (in ${ }^{\circ} \mathrm{C}$ ) and salinity (in psu) for the Changjiang outflow.

\begin{tabular}{ccccccccccccc}
\hline Month & January & February & March & April & May & June & July & August & September & October & November & December \\
\hline Discharge & 0.01 & 0.013 & 0.016 & 0.023 & 0.037 & 0.042 & 0.05 & 0.045 & 0.043 & 0.037 & 0.025 & 0.016 \\
Temperature & 8.0 & 9.0 & 12.0 & 14.0 & 18.0 & 22.0 & 25.0 & 25.0 & 23.0 & 18.0 & 14.0 & 10.0 \\
Salinity & 0.0 & 0.0 & 0.0 & 0.0 & 0.0 & 0.0 & 0.0 & 0.0 & 0.0 & 0.0 & 0.0 & 0.0 \\
\hline
\end{tabular}

this is not the focus of the model predictions used here, but rather to understand tidal effects on subtidal circulation.

Assuming linearity (Dean and Dalrymple 1984; Pugh 1987), corresponding tidal currents on open boundaries are

$\mathrm{V}_{\text {tidal current }}=\sqrt{g / D} \sum_{n=1}^{6} f_{n} S_{n} \cos \left(\omega_{n} t+\theta_{n}\right)$

where $D$ is the undisturbed water depth on open boundaries. The net water flow normal to each open boundary is therefore $\mathrm{V}_{\text {normal }}=\mathrm{V}_{\text {monthly mean current }}+\mathrm{V}_{\text {tidal current }}$, where $\mathrm{V}_{\text {monthly mean current }}$ is derived from monthly mean transport through open boundary as listed in Table 1. Starting from a motionless state, we spin up the model with and without tides for two years to eliminate the initial transients, and use the year-3 result to facilitate discussion.

\section{MODELED CO-TIDAL AND CO-RANGE CHARTS}

The marine atlas compiled by China Ocean Press (Chen et al. 1992) suggested two amphidromic points for $\mathbf{M}_{2}$ and $\mathrm{S}_{2}$ tides in Bohai Sea and its northern reach, Liaodong Bay. Some tidal models have since targeted the reproduction of the two amphidromic points as a measure of accuracy (Guo and Yanagi 1998). Apparently, the target must be met using sensible but often costly choice of parameters, among which the crucial ones are bed drag coefficient, grid size and accurate representation of coastline and bottom bathymetry, etc. Following Guo and Yanagi (1998) and Lefevre et al. (2000), we have adopted the same bed drag coefficient $\left(C_{d}=0.0015\right)$ in this study. Modeled sea level fields are harmonically decomposed for each major tidal constituent following Foreman and Henry (1979).
Figure 2 shows the consequent co-phase and co-range charts. For $\mathrm{M}_{2}$ and $\mathrm{S}_{2}$ tides, the three-dimensional model reproduces two amphidromic points each in Bohai and the Yellow Sea (Figs. 2a and b). The result resembles Yanagi et al. (1997), Guo and Yanagi (1998), Wu et al. (2011), and, most closely, Lefevre et al. (2000). The northern Bohai amphidromic point in Liaodong Bay is not as well developed as that seemingly suggested by the Chinese marine atlas (Chen et al. 1992). Since Liaodong Bay is a narrow inner reach of Bohai, better grid resolution with more accurate bathymetry representation seems necessary to better examine the amphidromic system. For $\mathrm{M}_{2}$ and $\mathrm{S}_{2}$ tides in the Yellow Sea, the model also reproduced the two well known amphidromic points, one to the south and the other off the northeastern tip of the Shandong peninsula. The modeled $\mathrm{M}_{2}$ amplitude off the western side of the Korean peninsula and Changjiang mouth is large (Fig. 2a), in agreement with Guo and Yanagi (1998) and Wu et al. (2011). For $\mathrm{K}_{1}$ and $\mathrm{O}_{1}$ tides, the model reproduced one amphidromic point each for the Yellow Sea and Bohai (Figs. 2c and d). Overall, the model captured the observed locations and amplitudes of amphidromic systems reasonably well. Diurnal amphidromic systems also develop better than semidiurnal ones. This is understandable because, through discretization, numerical models resolve longer waves better. South of the Changjiang mouth, active tidal propagation as coastal Kelvin waves leads to the conspicuous absence of amphidromic points.

\section{MEAN CURRENTS WITH AND WITHOUT TIDES}

Figure 3 shows the mean circulation at $2.5 \mathrm{~m}$ depth in summer (August) and winter (December) with and without tides. The average is over the first two spring-neap cycles of each month. Without tides, the averages (Figs. 3a and b) 
essentially show the monthly mean circulation patterns in August and December, respectively. Off northeast Taiwan, part of the Kuroshio intrudes onto the continental shelf of the East China Sea. The major portion turns from northward to eastward and thereafter follows the shelf break northeastward. The northward Taiwan Warm Current also enters the East China Sea from the Taiwan Strait and flows northeastward to join the main stream of the Kuroshio at about $28^{\circ} \mathrm{N}$. The summer subtidal circulation in the Yellow Sea and Bohai is weak. Judging from the weak condition, its ability to influence Changjiang plume should be very limited.

The mean surface circulation in winter (Fig. 3b) also matches expectations (Nitani 1972; He and White 1987; Lee and Chao 2003). Currents over the East China Sea are mostly downwind (southwestward) as expected. Under the north-northeast monsoon, the on-shelf Kuroshio intrusion off northeast Taiwan becomes more pronounced. The winter monsoon also blocks the northward Taiwan Warm Current from entering the East China Sea to a great extent, and produces a narrow band of southwestward China Coastal Current from Changjiang mouth to the Taiwan Strait. It should be noted that winter blocking of the Taiwan Warm Current is more persistent under monthly climatologic winds. On event-like time scales, the Taiwan Warm Current could regain strength briefly after occasional relaxations of northeast winter monsoon (Wu et al. 2007). We will briefly return to this point in sections 9 and 10. Farther north in the Yellow Sea and Bohai, the winter subtidal circulation also weakens with distance away from the East China Sea.

Including tides, the mean circulation after averaging (a)

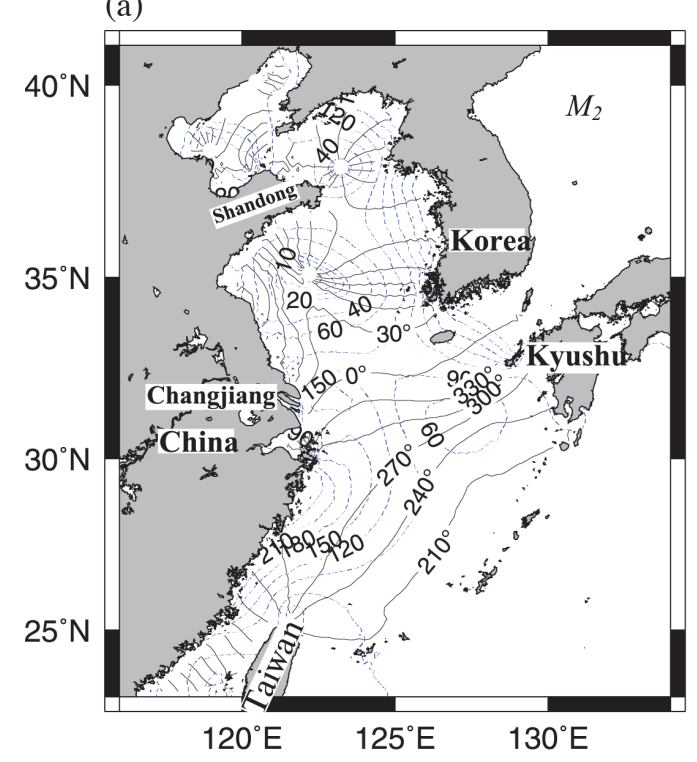

(c)

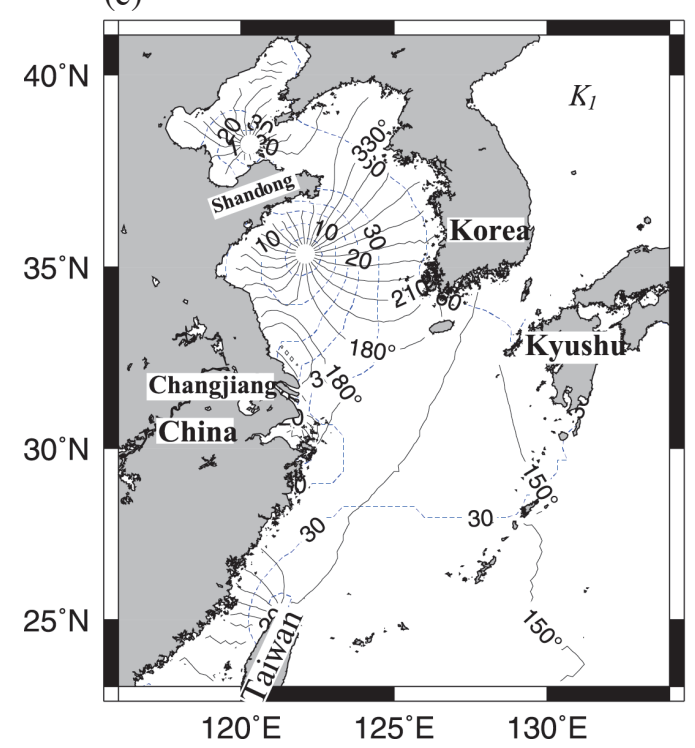

(b)

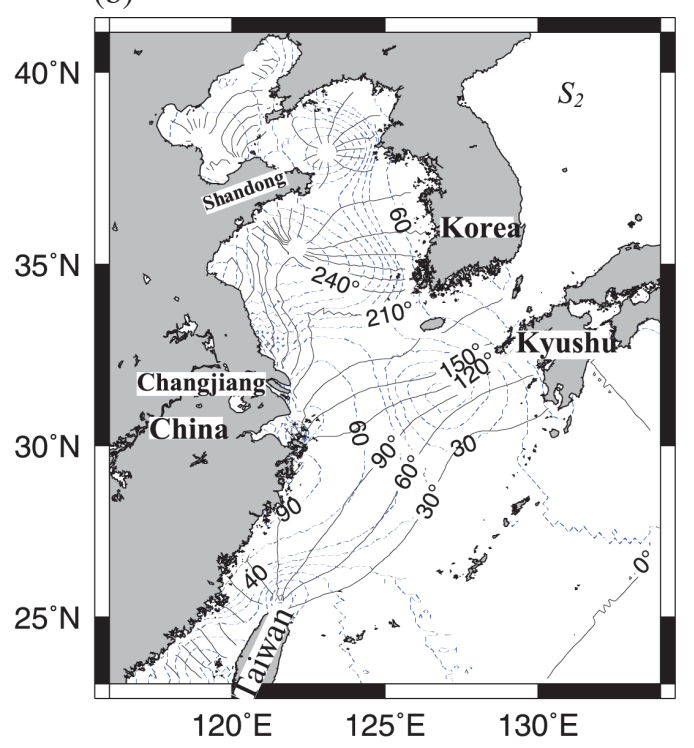

Fig. 2. Modeled co-tidal lines (solid lines in degrees) and co-range lines (dashed, blue lines in cm) for (a) $\mathrm{M}_{2}$ (b) $\mathrm{S}_{2}$ (c) $\mathrm{K}_{1}$ (d) $\mathrm{O}_{1}$ tides. 
(a)

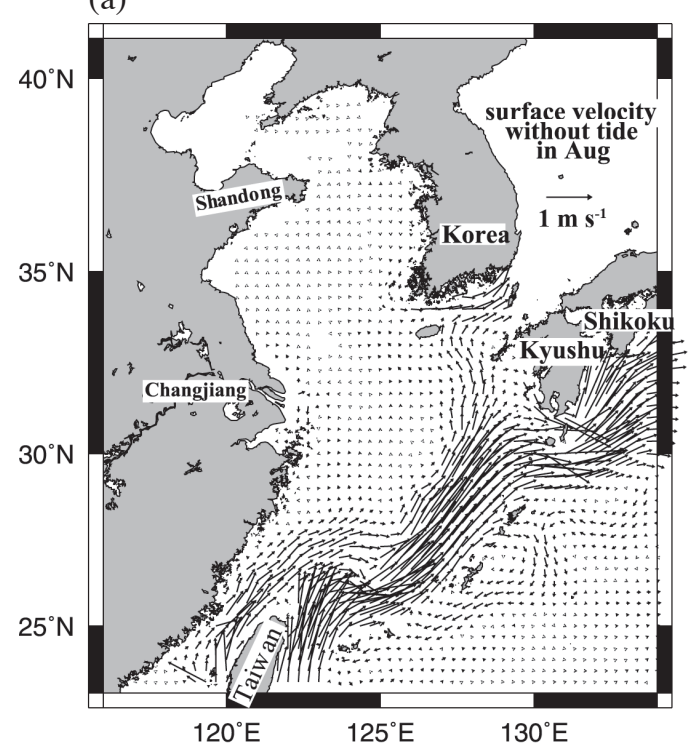

(c)

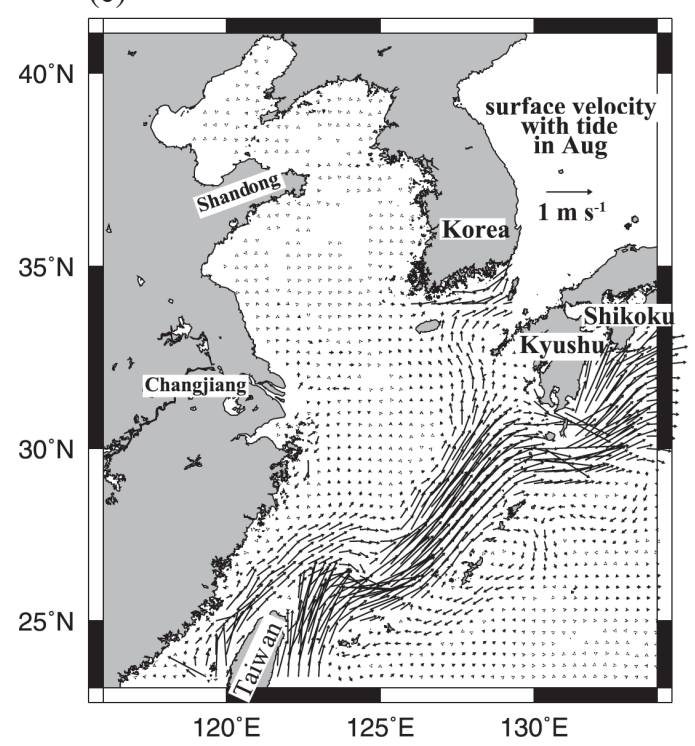

(b)

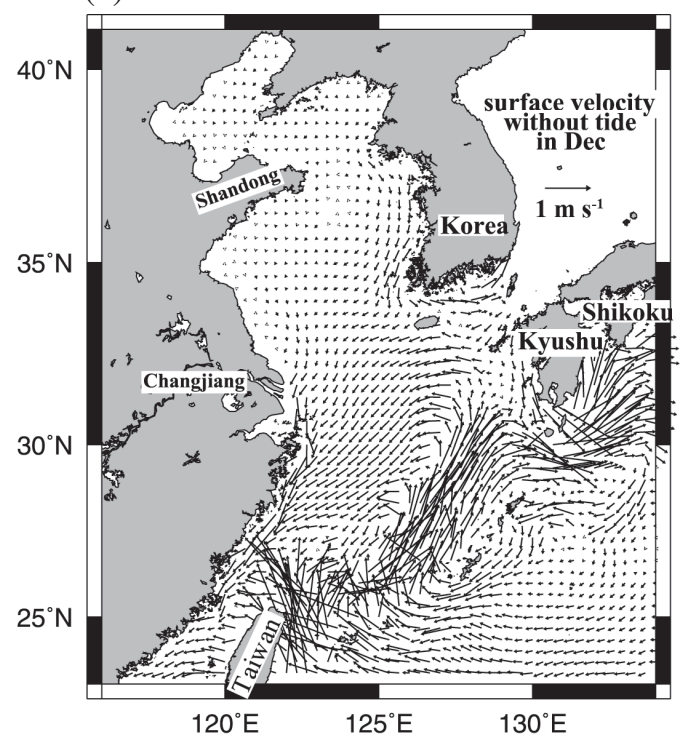

(d)

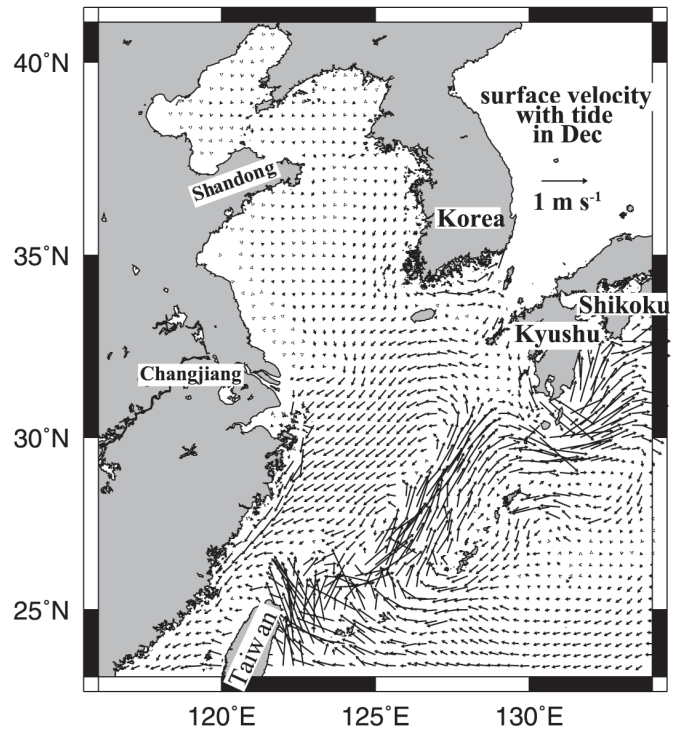

Fig. 3. Modeled surface flow fields (a) without tides for August, (b) without tides for December, (c) with tides for August and (d) with tides for December at $2.5 \mathrm{~m}$. All results are time-averaged over the first two spring-neap periods of the month.

over the first two spring-neap cycles in August (Fig. 3c) and December (Fig. 3d) seemingly differ little from the corresponding circulation without tides (Figs. 3a and b). Upon closer examination, however, with tides, it can be seen that seaward deflection of both the Taiwan Warm Current from the Taiwan Strait and the Kuroshio off northeast Taiwan occurs at lower latitudes. More details on this will be illustrated in section 9. As we shall see in sections 6 and 7, these tide-enhanced seaward deflections have consequences for the Changiiang plume dispersal and even subtle changes in the tidal residual flow. In the Yellow Sea and Bohai, the mean circulation remains more or less in the same calm condition whether tides are included or not.

\section{INTRA-TIDAL CIRCULATION}

Tides bring richness to the shelf circulation. Instantaneous snapshots of tidal currents are rather incomparable with the mean flow and therefore difficult to merge with the present context. We briefly illustrate and discuss below the tide-induced, instantaneous circulation anomalies within a diurnal period. We do so by subtracting subtidal, surface layer circulation (at $2.5 \mathrm{~m}$ depth) from corresponding circulation that includes tides. For the summer, Fig. 4 shows tideinduced circulation anomalies on August 1 at 6, 12, 18 and 24 hours. In general, tidal currents over the shelf are as comparably strong as the surface Kuroshio off the shelf break. 

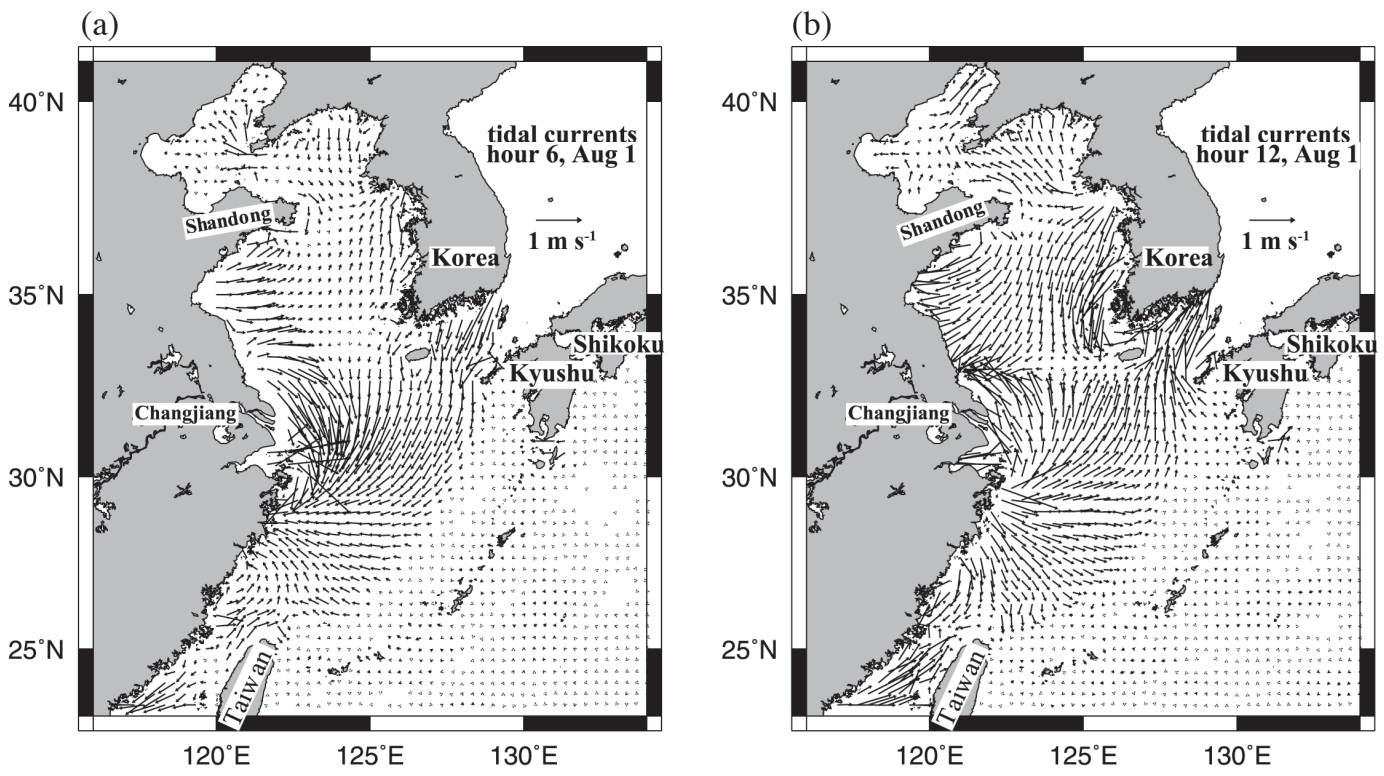

(c)

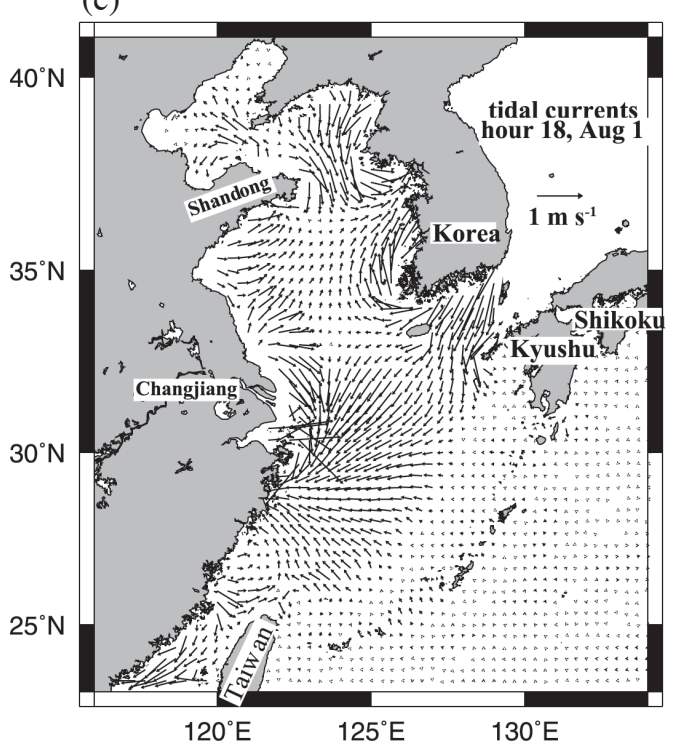

(d)

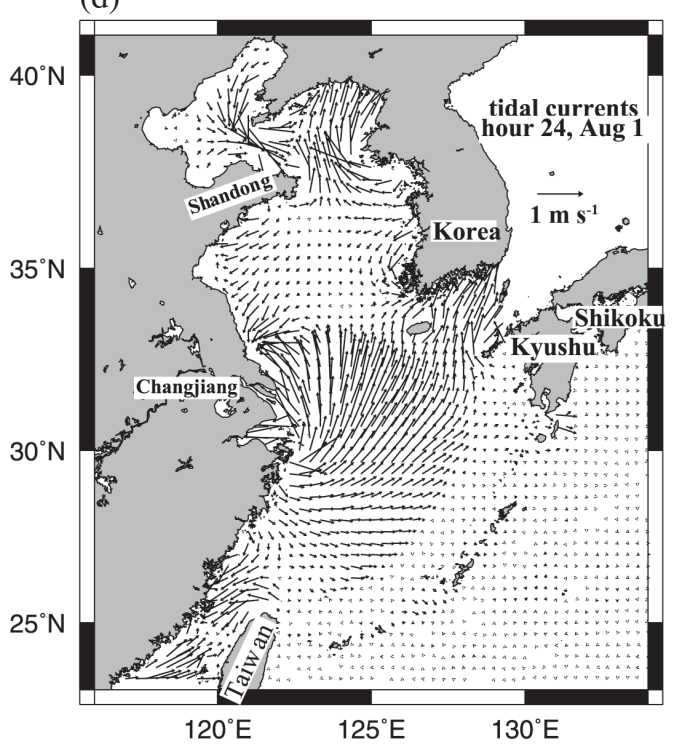

Fig. 4. Tide-induced surface flow anomalies at (a) 6, (b) 12, (c) 18 and (d) 24 hours on August 1.

This inspires confidence that tidal currents may exert their influence on the subtidal circulation over the shelf. We will elaborate this point in section 9. As noted in Guo and Yanagi (1998) and Lefevre et al. (2000), predominantly semidiurnal tidal currents are quite energetic off Changjiang mouth. These semidiurnal tides produce convergent and divergent tidal fronts to the north and south of Changjiang mouth. A convergence to the north is paired with a divergence to the south and, in half a semidiurnal cycle, a reverse pair would appear. Tidal currents are also notably strong in the Taiwan Strait, along the stretch of China coastline from Changjiang mouth southward, in the northern stretch of the East China Sea bordering Changjiang, and in the Yellow Sea and Bohai. Further, tidal currents converge and diverge twice daily near the northern Taiwan Strait; observations lend support to this (Hu et al. 2010). Corresponding winter features, though different in strength because of changes in stratification and wind stress, are similar and will not be illustrated here.

\section{CHANGJIANG PLUME DISPERSAL}

Without tides, Figs. 5a and b show the instantaneous sea surface salinity (SSS) to highlight the Changjiang plume on August 1 and December 1, respectively. In summer (Fig. 5a), the generally northward current over the shelf, mostly coming from the Taiwan Strait, suppresses the would-be southward plume expansion. Rather, the plume disperses mainly to the northeast. In winter (Fig. 5b), the north-northeast monsoon 

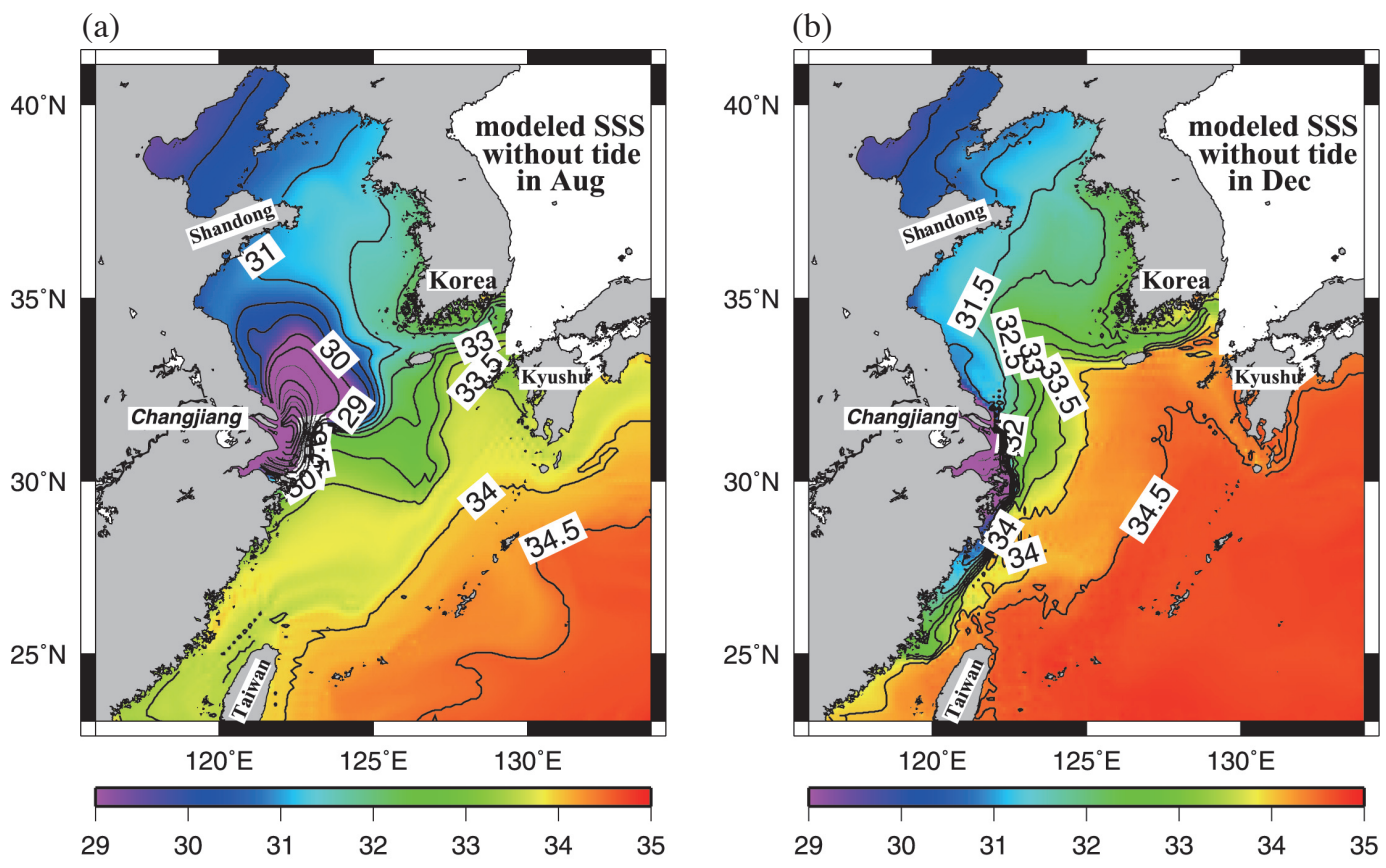

(c)

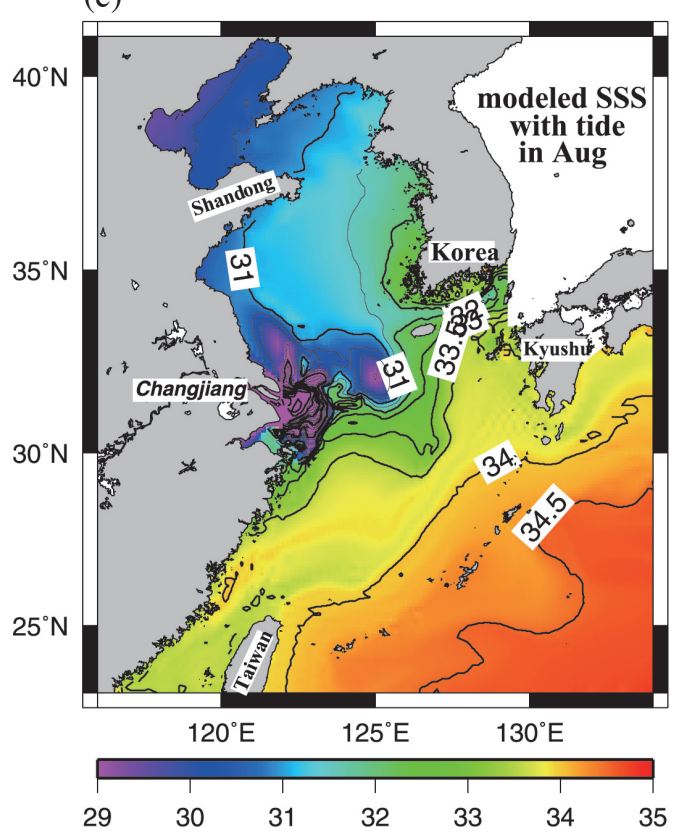

(d)

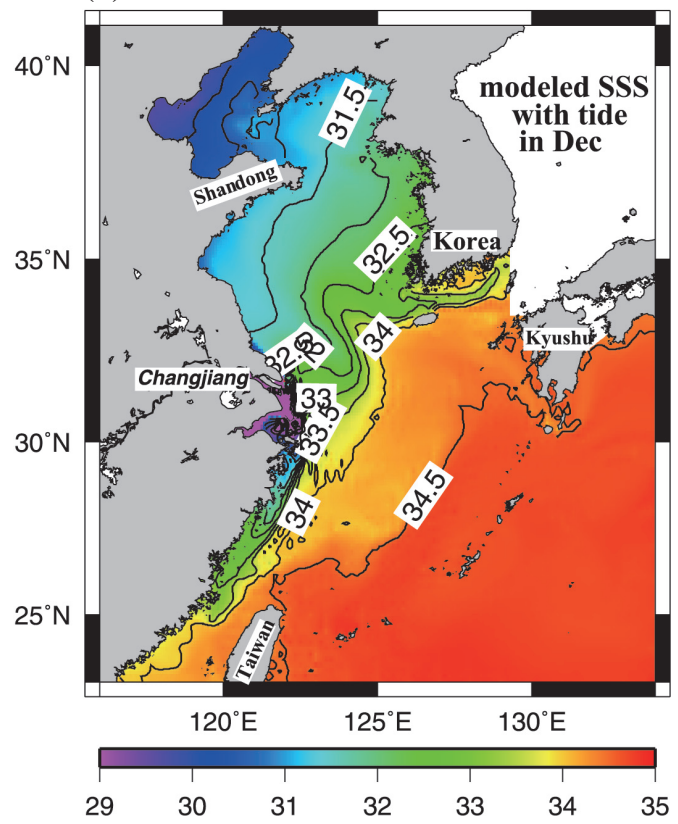

Fig. 5. Instantaneous sea surface salinity (SSS) (in psu) for the Changiiang plume: (a) without tides on August 1, (b) without tides on December 1, (c) with tides on August 1 and (d) with tides on December 1.

essentially eliminates most of the northward plume excursion into the Yellow Sea. In its place is the salinity intrusion into the Yellow Sea. Further, the north-northeast monsoon forces the plume to intrude southwestward as a narrow band hugging the coast of China, reaching as far south as the middle reaches of the Taiwan Strait.

By including tides, Figs. 5c and d show the corresponding SSS on August 1 and December 1, respectively. In summer (Fig. 5c), tidal currents shift the core of the plume slightly to the south of Changjiang mouth and therefore bring the model result closer to observations (e.g., Moon et al. 2010). The northward intrusion into the Yellow Sea is much reduced. Conceivably, tide-induced flushing reduces the residence time of Changjiang plume in the Yellow Sea. The southward plume expansion along the China Coast is also visibly enhanced. The plume northeast of the Changjiang mouth becomes more saline and less expansive. Further, tides break the otherwise single core northeast of the 
Changjiang mouth (Fig. 5a) into two (Fig. 5c), as delineated by 31 psu contours. The offshore detachment of the summer Changjiang plume has been discussed (Lie et al. 2003) and reproduced by numerical models (e.g., Moon et al. 2010; Wu et al. 2011).

In winter, tides also perturb Changjiang plumes (Fig. 5d). In the Yellow Sea, tides cause the winter plume to recede farther south (Fig. 5c). Apparently, periodic tides flush out remnants of plume water north of Changjiang mouth from the preceding summer at a faster rate. By comparing Figs. $5 b$ with $d$, tidal effects on the winter plume dispersal south of the Changjiang are less clear and need clarification as shown in Fig. 6.

To quantify further, Figs. $6 \mathrm{a}$ and $\mathrm{b}$ show instantaneous tide-induced SSS anomalies on (a) August 1 and (b) December 1 . These anomalies are derived by subtracting the subtidal plume (without tides) from the corresponding simulation with tides. August 1 (Fig. 6a) is a typical summer case; (a)

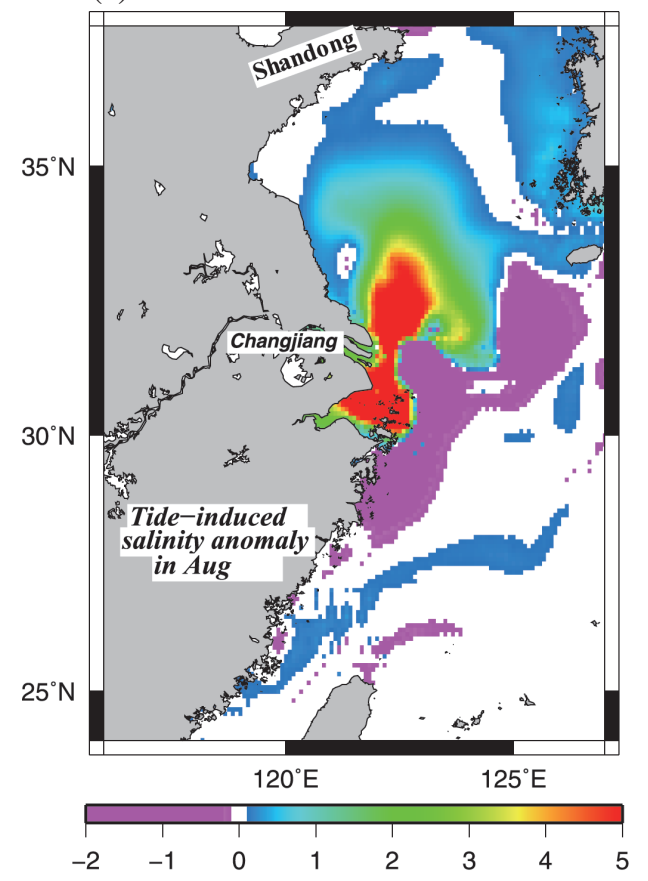

(c)

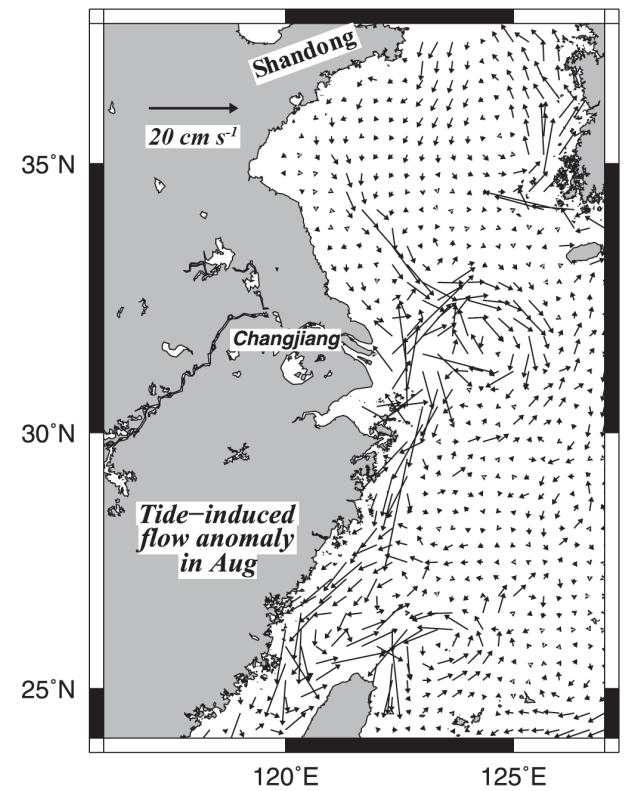

(b)

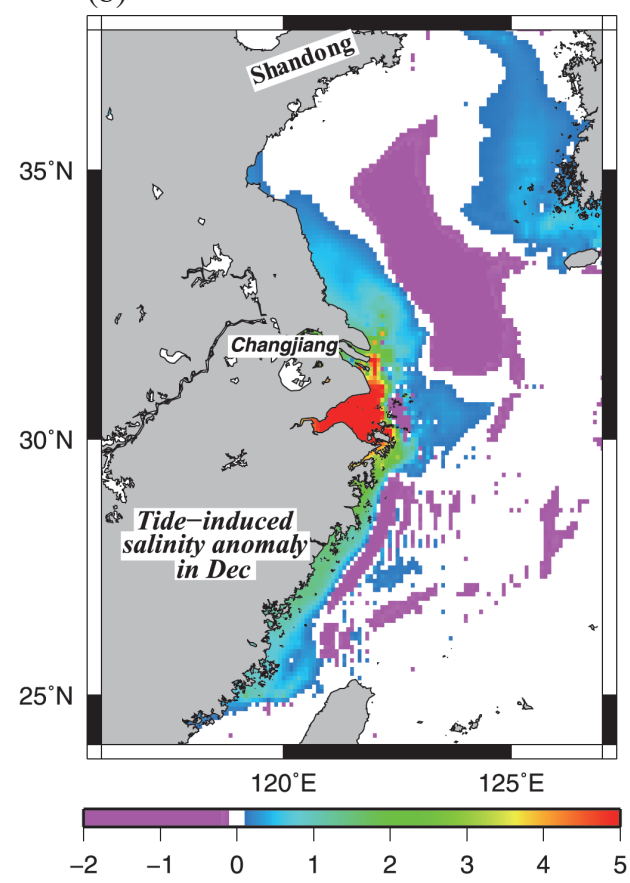

(d)

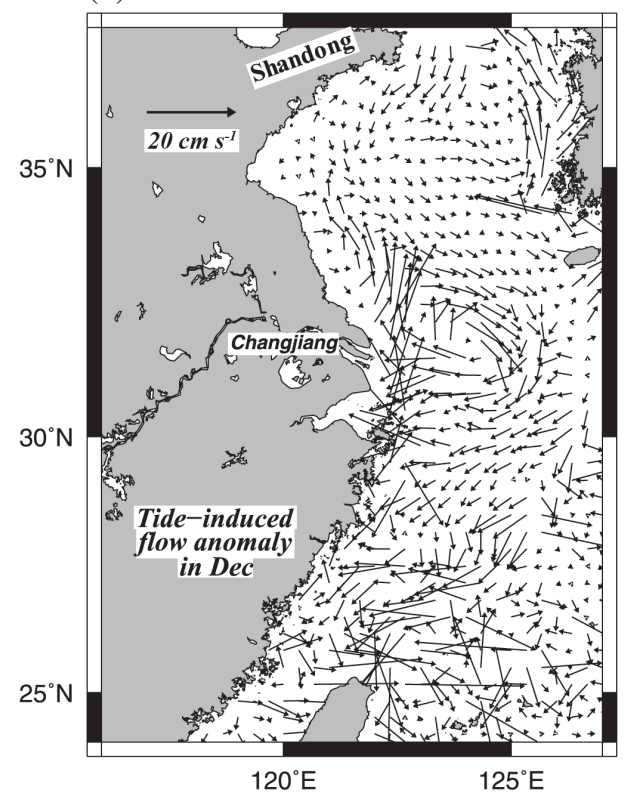

Fig. 6. Tide-induced SSS anomalies (in psu) on (a) August 1 and (b) December 1. Positive and negative values indicate tidal enhancement and reduction, respectively. Also shown are tidal residual currents at $2.5 \mathrm{~m}$ for (c) August and (d) December. 
the near-shore anomaly is positive seaward, north and south of the Changjiang mouth, indicating much diluted Changjiang plume (or enhanced SSS) due to the presence of tides. Farther seaward and well south of the Changjiang mouth, the SSS anomaly is negative, indicative of freshening by tide-induced plume expansion. In winter, Figure $6 \mathrm{~b}$, tidal effects also reduce the plume concentration (or enhance SSS) seaward, north and south of Changjiang mouth.

We briefly comment on the summer plume detachment below in support of previous numerical findings (Moon et al. 2010; Wu et al.2011). Figure 7 illustrates an eddy detachment event from August 12 to August 21. On top of the four-panel set is the model-derived sea level variation at the Chanjiang mouth and the times of snapshots during spring tide (time 1) and neap tide (time 2). Left panels (a1 and 2) show the model-derived SSS using the default NCEP monthly climatology winds, whereas right panels (b1 and 2) show the corresponding results if the model is driven by the monthly climatology winds of Hellerman and Rosenstein (1983). Independent of wind products, plume detachment occurs preferably during spring tides (a1 and b1). The vigor of the detached lens and its subsequent northeastward movement is proportional to the wind strength. In August, the average southeasterly wind between $28^{\circ}$ and $36^{\circ} \mathrm{N}$ is only 0.03 dyne $\mathrm{cm}^{-2}$ with NCEP climatology, but is equal to 0.2 dyne $\mathrm{cm}^{-2}$ with Hellerman-Rosenstein climatology. The latter drives a more vigorous and clear-cut lens shedding (b1 and 2). Further, lens shedding owes its existence to tidal strength. A $50 \%$ reduction of tidal strength, for example, would eliminate the summer plume detachment.

\section{TIDAL RESIDUALS}

Tides shift the Changjiang plume southward in summer but not in winter. To investigate further, Figs. $6 \mathrm{c}$ and dillustrate current anomalies or tidal residual currents, derived by subtracting time-averaged subtidal currents at $2.5 \mathrm{~m}$ depth (without tides) from corresponding simulations with tides for August and December, respectively. The averages are over the first two spring-neap cycles of the month. This tidal residual current is an intuitive way to measure how tides redistribute their energy in the presence of barotropic and baroclinic tidal propagation, mesoscale density-flow variations, and background tidal dissipation. We choose $2.5 \mathrm{~m}$ to illustrate the tidal residual current but also note its vertical coherence and slow attenuation with depth.

In the summer, using August as an example (Fig. 6c), notably strong tidal residual flow is northward off western Korea, in agreement with earlier tidal models with or without ambient stratification (Lee and Beardsley 1999). Off the Changjiang mouth, the residual flow is an anticyclonic eddy with a strong seaward flow and weak return flow to the south. The seaward residual flow could conceivably enhance the ability of the plume to detach offshore. Off from a wide estuary mouth such that the earth rotation is important, an anticyclonic eddy develops better especially if the width of the mouth is comparable to the baroclinic Rossby radius (Chao 1990). Of particular importance to the Changjiang plume dispersal is a southward coastal tidal residual flow from the Changjiang mouth to the Taiwan Strait. This tidal residual current, ranging up to $17 \mathrm{~cm} \mathrm{~s}^{-1}$, is vertically coherent and attenuates slowly with depth. Recall that, in the absence of tides, the subtidal current from the Taiwan Strait to the Changjiang mouth is northward (Fig. 3a). The southward tidal residual flow essentially offset the northward subtidal current. The cancellation would reduce the northward pressure gradient force that pushes the Changjiang plume northeastward toward the Yellow Sea. It also allows the Changjiang plume to disperse southward along the China coastline.

In winter (Fig. 6d), the northward tidal residual flow grows even stronger off the west coast of the Korea peninsula. Off Changjiang, the residual anticyclonic eddy also becomes stronger. As in summer, the seaward portion of the flow associated with the anticyclone is capable of inducing net offshore plume movement off the Changjiang mouth. However, the much reduced Changjiang discharge makes isolated lens shedding difficult. South of the Changjiang mouth, the coastal tidal residual flow fails to organize to enhance southward transport of the Changjiang plume. In consequence, tides reduce southward expansion of the Changjiang plume along China coast in winter (Fig. 6b).

The summer residual flow enhances the Changjiang plume dispersal. We illustrate its vertical structure along $27^{\circ} \mathrm{N}$. To establish the background state first, Fig. 8 shows the mean meridional flow (a), temperature (b), salinity (c) and density (d) along $27^{\circ} \mathrm{N}$ in the top $100 \mathrm{~m}$ averaged over the first two spring-neap periods of August. The results are from the experiment that excludes tides; its corresponding surface circulation was shown in Fig. 3a. The background state harbors a northward mean flow in water depths shallower than $90 \mathrm{~m}$ (Fig. 8a). Farther seaward, there is a return (southward) flow over the mid-shelf. Even farther seaward, the Kuroshio Current is strongly northward. The density structure in support of geostrophic currents (Fig. 8d) is mainly controlled by temperature (Fig. 8b) rather than by salinity (Fig. 8c).

Tidal residual signals along $27^{\circ} \mathrm{N}$ (Fig. 9) tell more. Again, residuals are defined as the average of model results with tides minus corresponding ones without tides over the first two spring-neap periods in August. In regions shallower than $50 \mathrm{~m}$, the mostly southward, barotropic residual current (Fig. 9a) carries colder, fresher and lighter waters southward (Figs. 9b, c, and d); these are remnants of southward Kelvin wave propagation. Over the mid-shelf, the tidal residual current becomes increasingly baroclinic and northward (Fig. 9a). In addition, tidal residuals bring a mid-depth core of warmer, fresher and lighter anomalies to the mid-shelf (Figs. 9b, c, and d). The region off northern tip of Taiwan is famously known for the confluence of Kuroshio water 


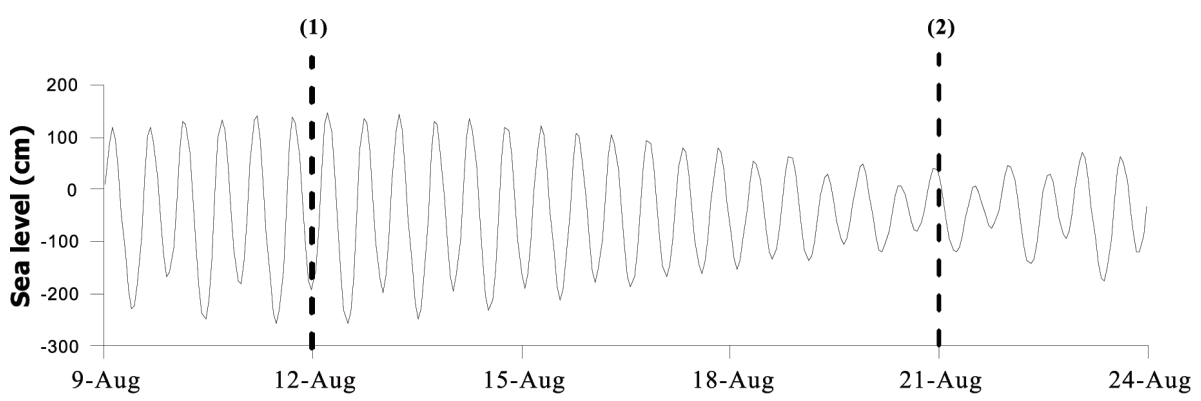

(a1)

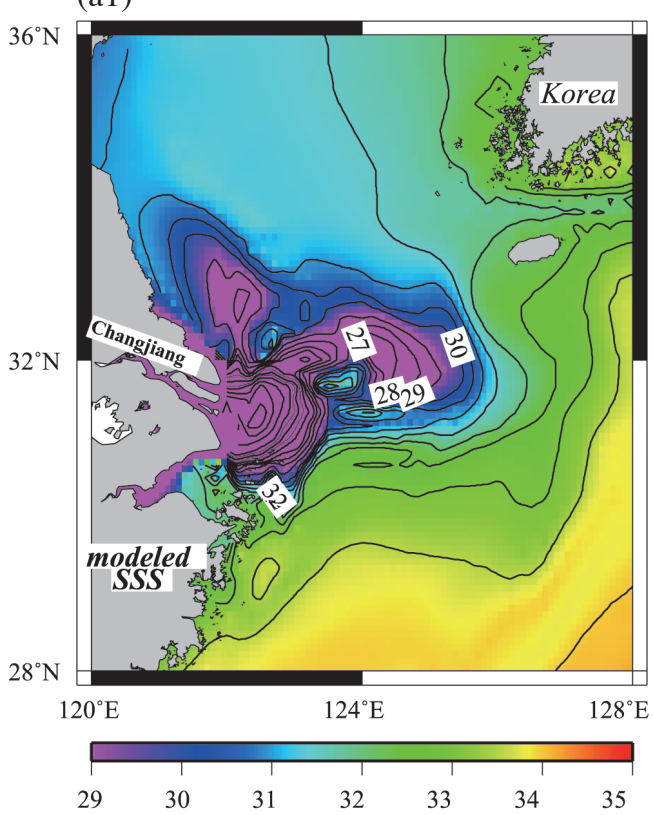

(a2)

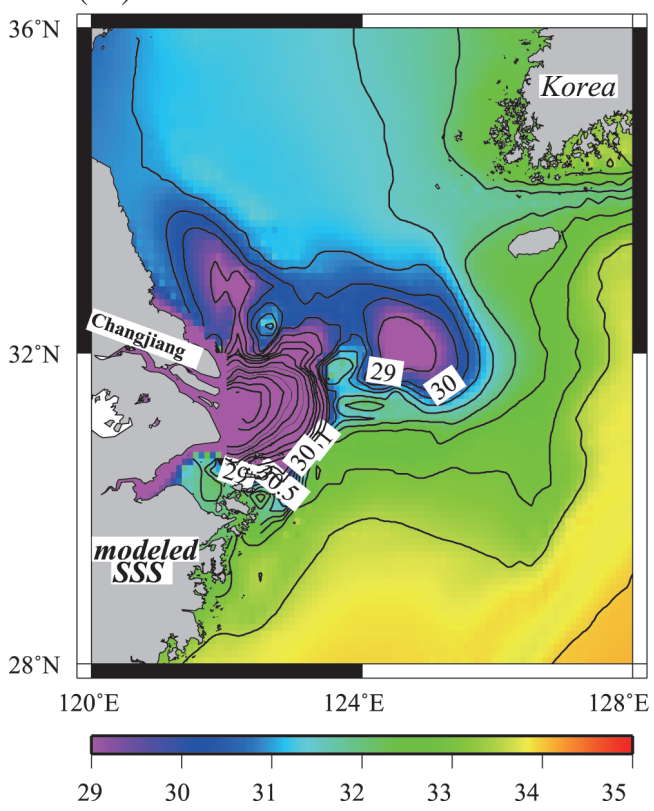

(b1)

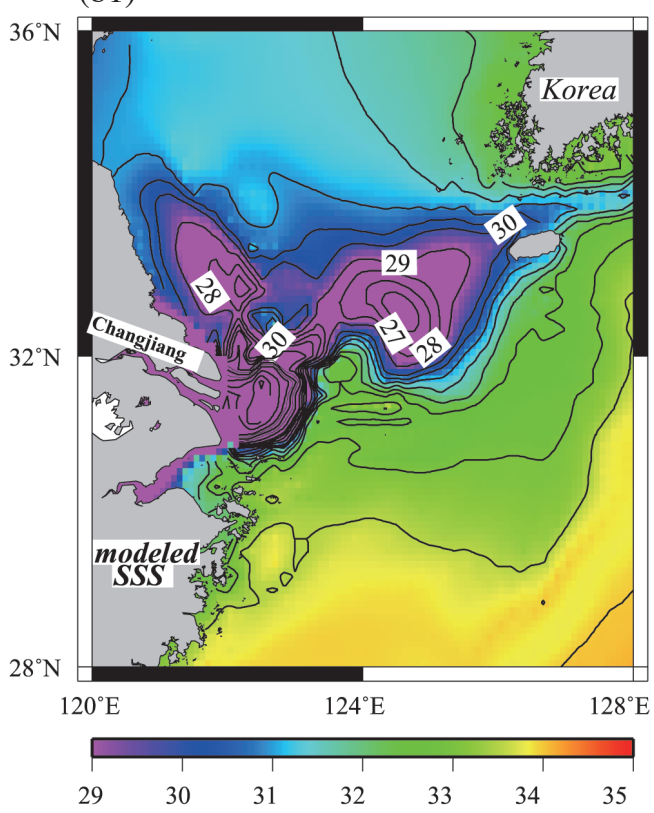

(b2)

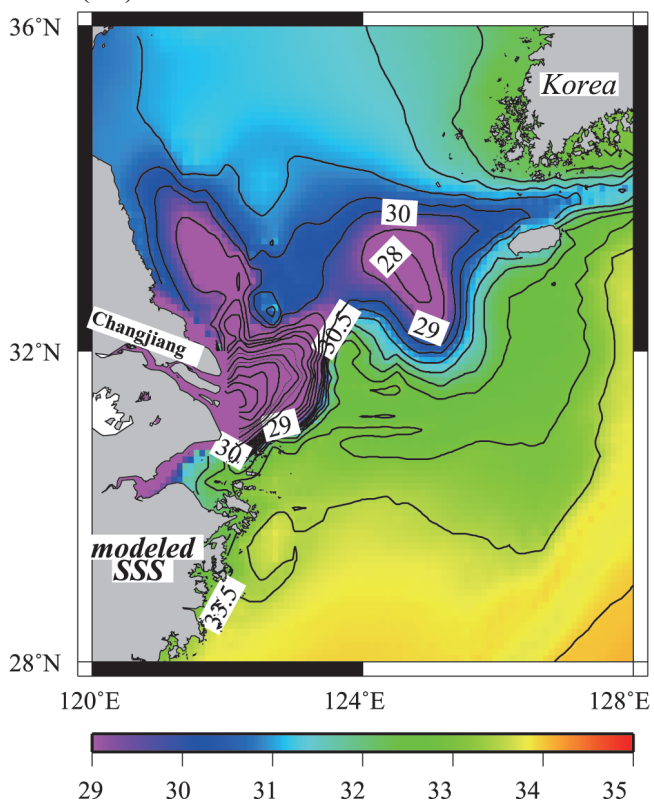

Fig. 7. Summer Changjiang plume detachment as indicated by SSS (in psu). On top of the four-panel set is the modeled sea level elevation at the Changjiang mouth from August 9 to 24 with two time marks during spring tide (time 1) and neap tide (time 2). Below sea level time series, left panels (a1 and 2) are under NCEP monthly climatology wind at time 1 (August 12) and time 2 (August 21), respectively. Right panels (b1 and 2) are corresponding results under Hellerman-Rosenstein monthly climatology wind. 


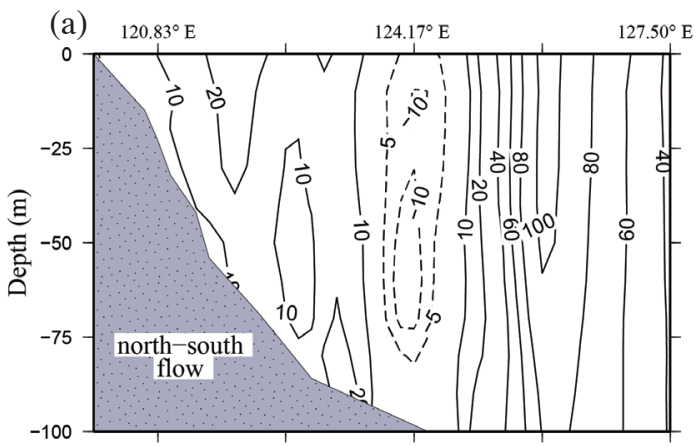

(b)
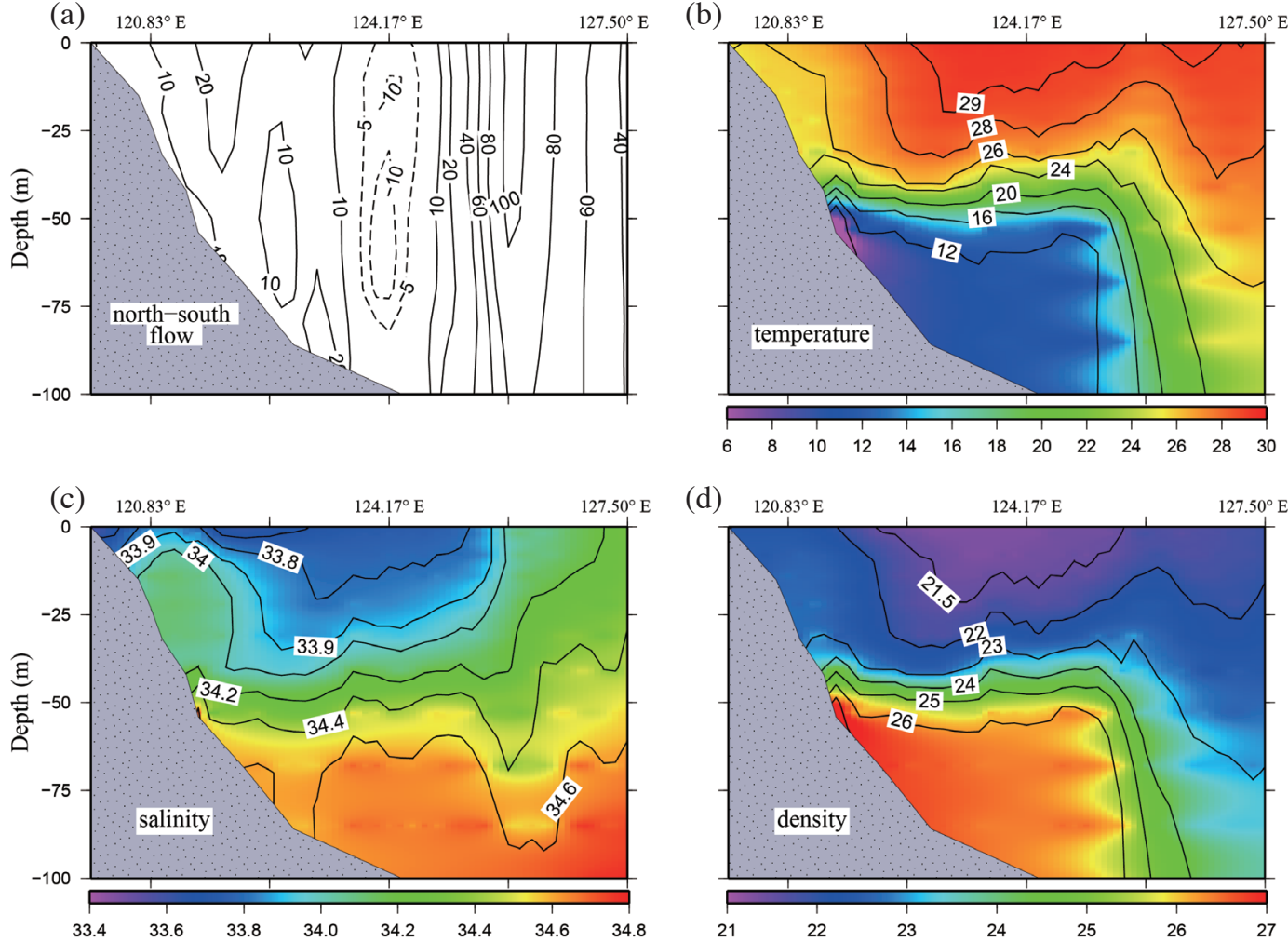

(d) $120.83^{\circ} \mathrm{E}$

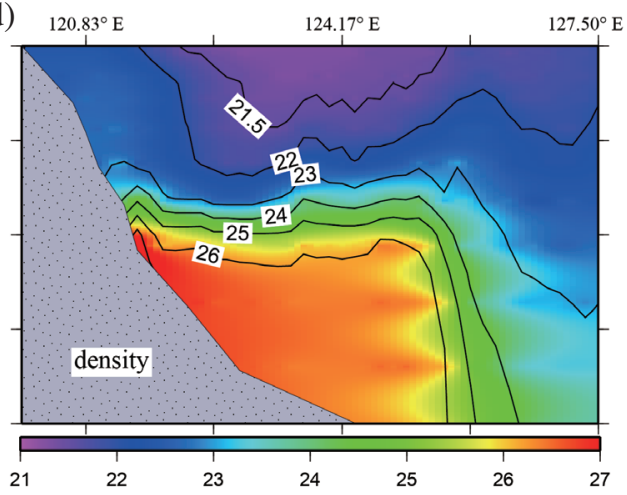

Fig. 8. A zonal $\left(27^{\circ} \mathrm{N}\right)$ section of mean meridional flow in $\mathrm{cm} \mathrm{s}^{-1}$ (a), temperature in ${ }^{\circ} \mathrm{C}(\mathrm{b})$, salinity in psu (c) and density in $\sigma_{\mathrm{t}}(\mathrm{d})$ averaged over the first two spring-neap periods of August in the top $100 \mathrm{~m}$, derived from the model that excluded tides. Northward current contours in (a) are positive.
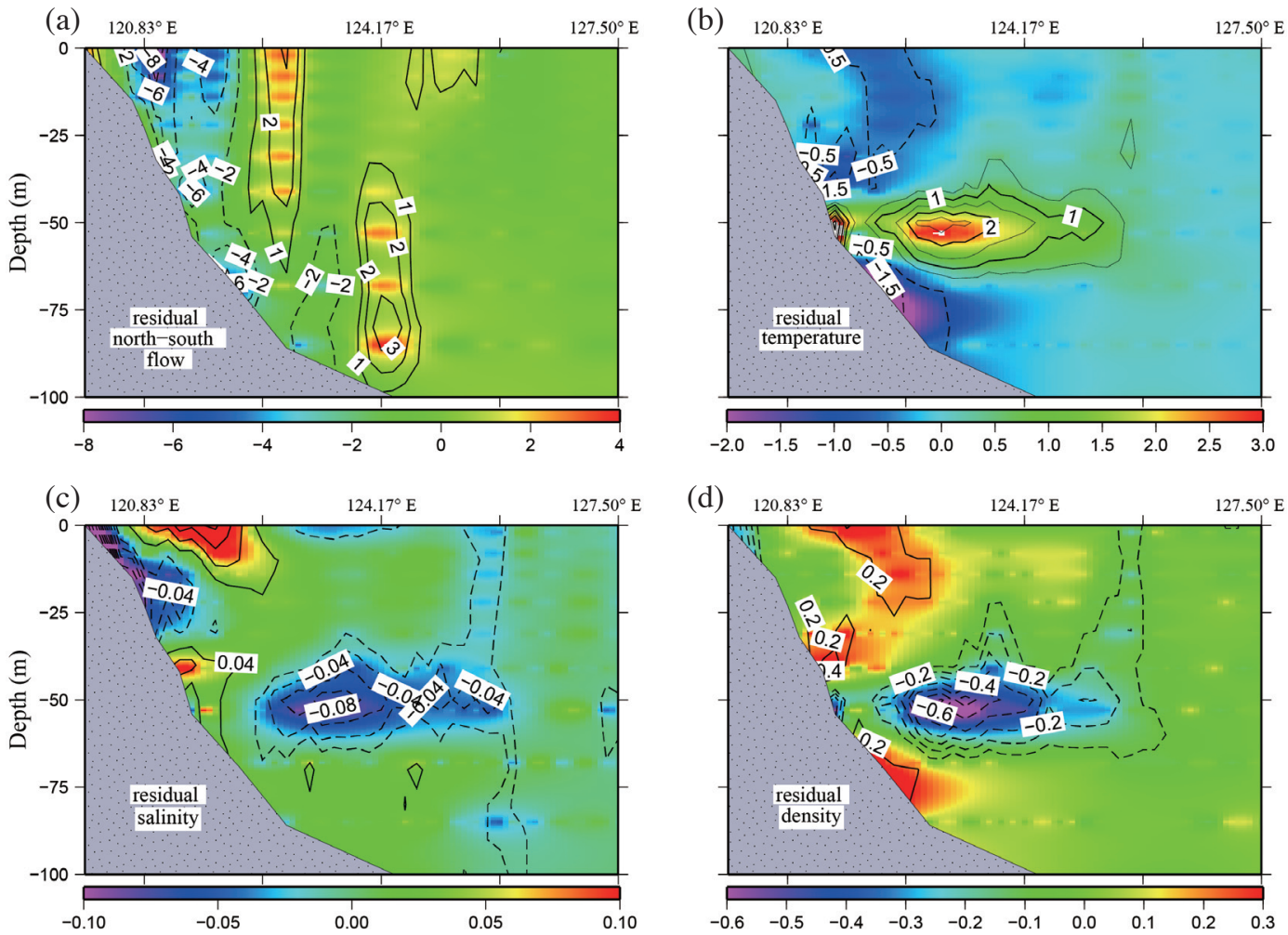

Fig. 9. A zonal $\left(27^{\circ} \mathrm{N}\right)$ section of tidal residuals: (a) north-south flow in $\mathrm{cm} \mathrm{s}^{-1}$, (b) temperature in ${ }^{\circ} \mathrm{C}$, (c) salinity in psu and (d) density in $\sigma_{\mathrm{t}}$. All residuals are averaged over the first two spring-neap periods of August in the top $100 \mathrm{~m}$, derived from the difference between models with and without tides. Positive anomalies are northward, warmer, saltier or denser. 
and Taiwan Strait water; the latter is warmer, fresher and lighter. Tracking the mid-depth core latitude by latitude in our model further would confirm its Taiwan Strait origin. In other words, the northward tidal residual flow over the midshelf north of Taiwan in summer (Fig. 6c) enhances the contribution of Taiwan Strait waters to the region. Obviously, these residual anomalies will not show up if the temperature, salinity and density are homogeneous in the north-south direction before the tidal effects occur. The suspended core of mid-shelf temperature, salinity and density residuals in mid-

(a)

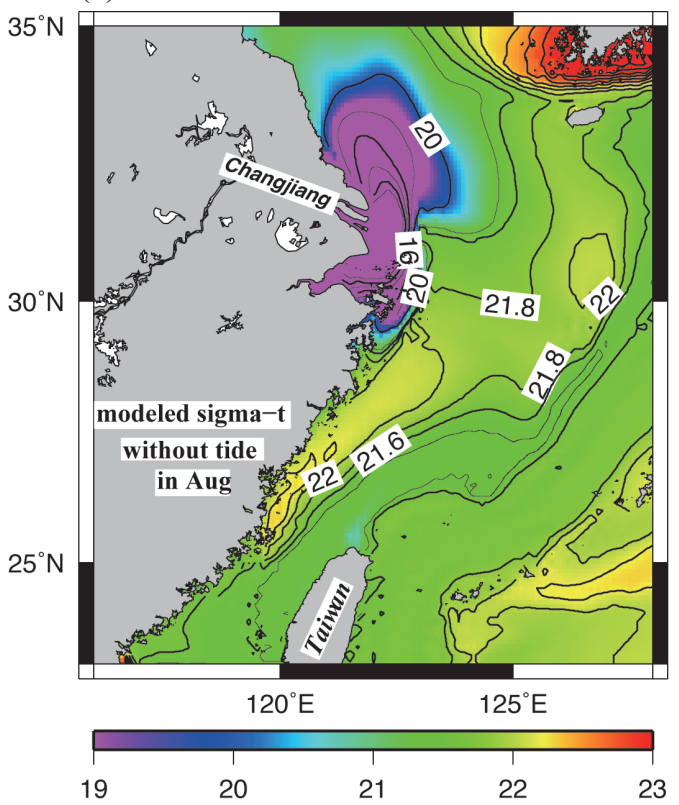

(c)

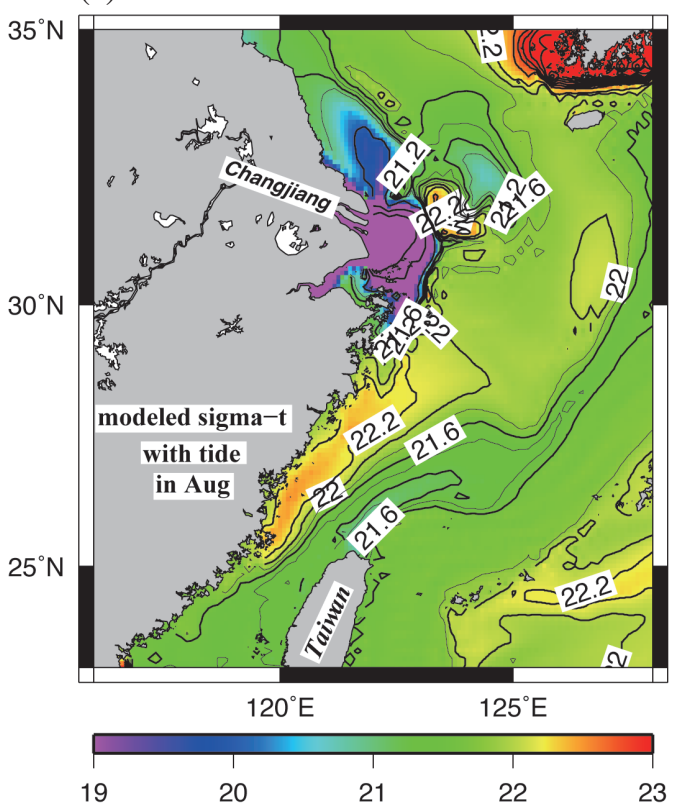

depths must be preconditioned by corresponding north-south gradients before tidal effects are included in the model.

\section{SUMMER UPWELLING OFF SOUTHEAST CHINA}

Figures $10 \mathrm{a}$ and $\mathrm{b}$ show the instantaneous density $\left(\sigma_{\mathrm{t}}\right)$ fields at $2.5 \mathrm{~m}$ depth without tide in the East China Sea in summer (August 1) and winter (December 1), respectively. In summer (Fig. 10a), the density field is understandably low

(b)

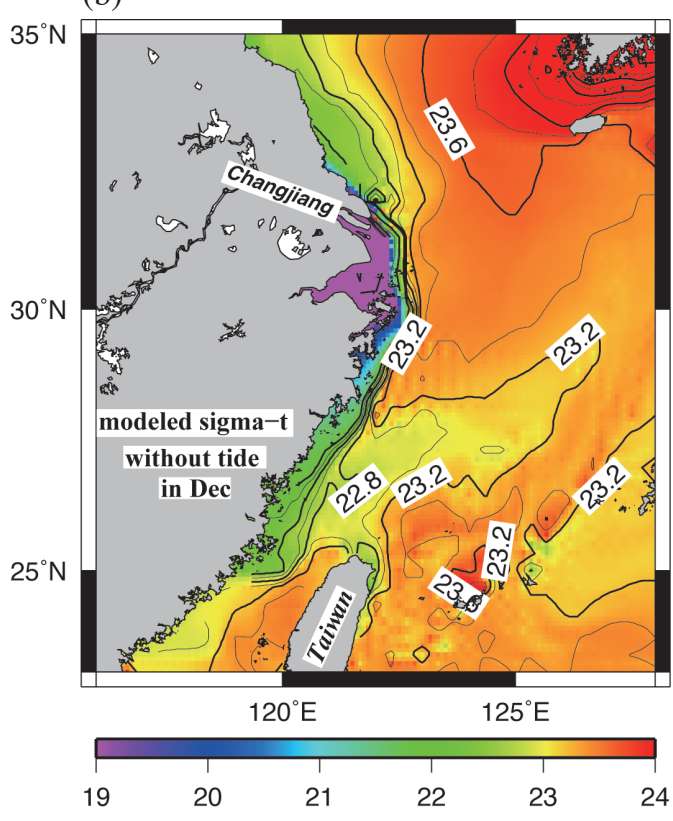

(d)

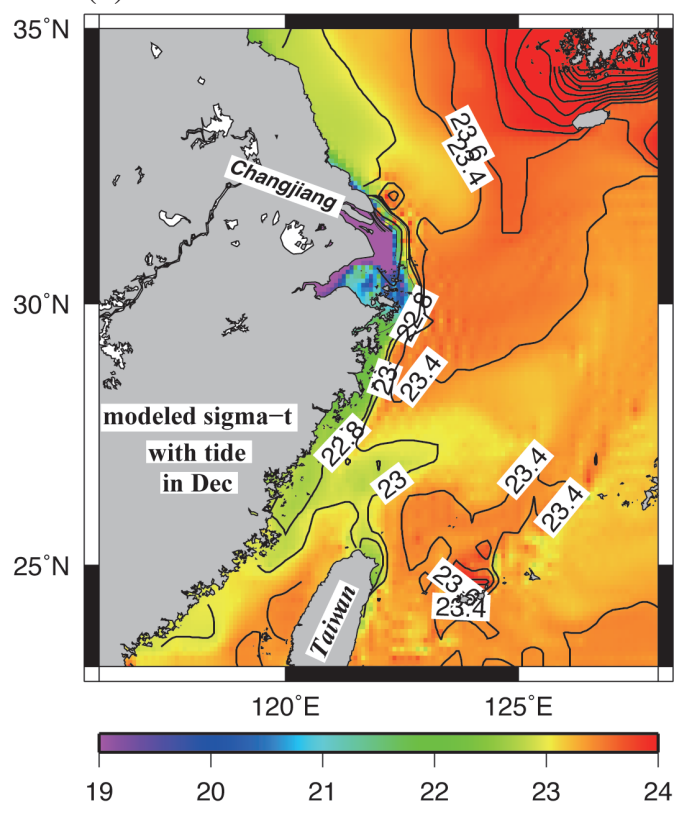

Fig. 10. Modeled density fields, $\sigma_{\mathrm{t}}\left(\mathrm{kg} \mathrm{m}^{-3}\right)$, at $2.5 \mathrm{~m}$ depth (a) without tides on August 1, (b) without tides on December 1, (c) with tides on August 1 and (d) with tides on December 1. 
in the Changjiang plume region because of freshening. South of the Changjiang plume, near-shore upwelling increases density modestly all the way to the northern reaches of Taiwan Strait. The near-shore upwelling is vertically coherent, extending through the entire water column. The August monsoon wind (Fig. 1b) is not even upwelling-favorable. As we will illustrate later, the near-shore upwelling coexists with the Taiwan Warm Current. In winter (Fig. 10b), the northnortheast monsoon drives Changjiang plume water down the coast, creating a coastal band of light water all the way to the Taiwan Strait. The winter north-northeast monsoon is strong and downwelling-favorable. It also suppresses the would-be northward intrusion of Taiwan Warm Current into the East China Sea and hence inhibits the near-shore upwelling off southeast China.

Including tides, Figs. 10c and d show corresponding $\sigma_{\mathrm{t}}$ fields in summer (August 1) and winter (December 1), respectively. In summer (Fig. 10c), tides reduce the buoyant pool off the Changjiang mouth considerably, but the nearshore upwelling off southeast China is markedly enhanced by tides. As we will further elaborate later, tides not only enhance the near-shore upwelling but also alter the path of the Taiwan Warm Current. In winter (Fig. 10d), tides slightly impede southward propagation of Changjiang-forced, buoyant coastal jet along southeast coast of China; the near-shore upwelling is conspicuously absent off southeast China.

\section{TIDAL EFFECTS ON THE EAST CHINA SEA MEAN FLOW IN SUMMER}

To see tidal effects on the East China Sea summer mean flow in another light, Fig. 11 shows a composite, close-up derived from Figs. 3a and 6c. The vector plot, from Fig. 6c, is the tidal residual flow at $2.5 \mathrm{~m}$ in August, derived by subtracting mean flow without tides from the corresponding flow field with tides and then averaging over the first two spring-neap periods of the month. Curved, broad arrows indicate the axis of Taiwan Warm Current (in gray) and the Kuroshio (in black) in the absence of tides, derived from the mean flow after averaging over the first two spring-neap periods of August at $2.5 \mathrm{~m}$ (Fig. 3a). Both currents are deflected seaward in the lower East China Sea. Tidal effects on the Taiwan Warm Current and the on-shelf intrusion of the Kuroshio meander are clear in Fig. 11. Following each meander current seaward, tide-induced flow anomalies weaken or offset the current on the left side but strengthen or rebuild it on the right side. In other words, they essentially force the Taiwan Warm Current and Kuroshio meander over the shelf to deflect to deeper waters at lower latitudes. The deflection to deeper water has interesting consequences.

Why do tides shift Taiwan Warm Current and on-shelf intrusion of Kuroshio meander southward? The southern end of the East China is connected to the Taiwan Strait. From the Changjiang mouth southward, the dominant tides in the
East China Sea consist of a series of coastal Kelvin waves propagating southward. In half of the tidal cycle (or wavelength) with high sea level, both tidal current with higher water level and therefore slightly faster tidal propagation are southward, pounding more strongly on the southern end of the East China Sea. In another half of the tidal cycle (or wavelength) with low sea level, tidal current with lower water level is northward while the slightly slower tidal propagation is still southward. As far as the receiving (southern) end of the East China Sea is concerned, this half period of withdrawal is gentler. After a continuous series of stronger southward pounding and gentler northward withdrawal, the net tidal effect could conceivably force the Taiwan Warm Current to deflect seaward at lower latitudes in summer.

The foregoing argument requires an illustration of how tides redistribute the pressure. Figure 12 shows the tide-induced pressure anomaly at $2.5 \mathrm{~m}$ depth in August. The pressure anomaly, accounting for horizontal variations of both sea level and density, excludes subtidal contributions by subtracting the pressure field without tides from corresponding pressure field with tides and then averaging over the first two spring-neap periods of August. Focusing on the lower East China Sea from the Changjiang mouth southward, the tidal residual after a series of Kelvin wave propagation with alternating highs and lows produces an inner-shelf band of high pressure residuals along the southeast coast of China. This inner shelf high pressure anomaly makes a cyclonic Uturn in the Taiwan Strait and, after exiting the Taiwan Strait,

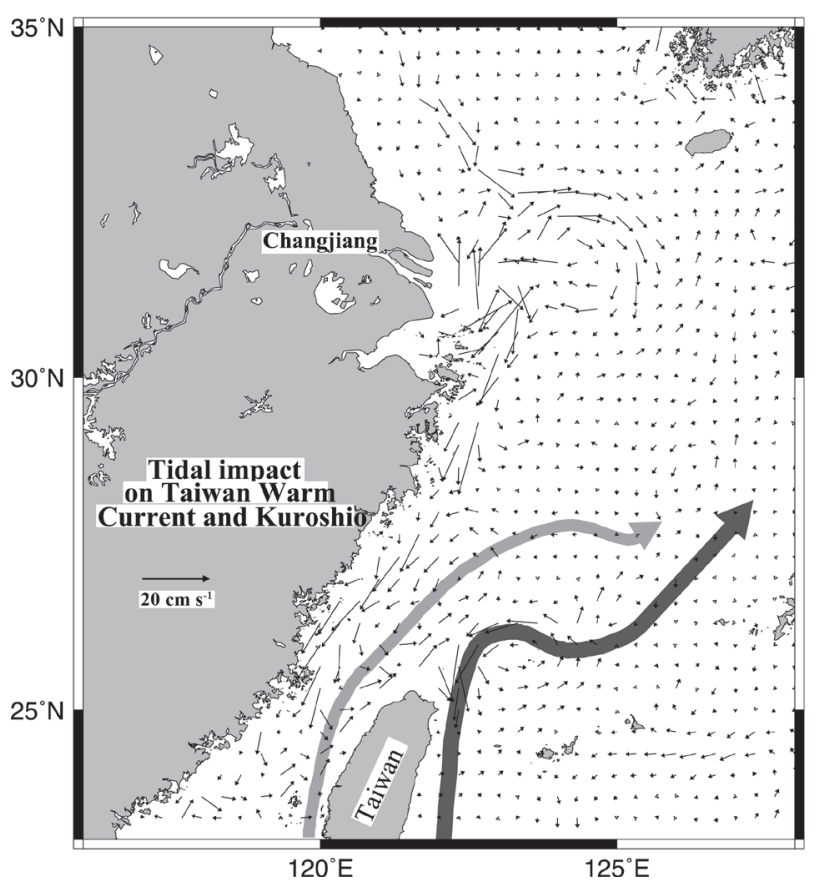

Fig. 11. A close-up of the summer axis of the Taiwan Warm Current (in gray, broad and curved arrow) and Kuroshio (in black, broad and curved arrow) derived from the model results at $2.5 \mathrm{~m}$ depth without tides, superimposed on the tide-induced flow anomaly at $2.5 \mathrm{~m}$ depth. 


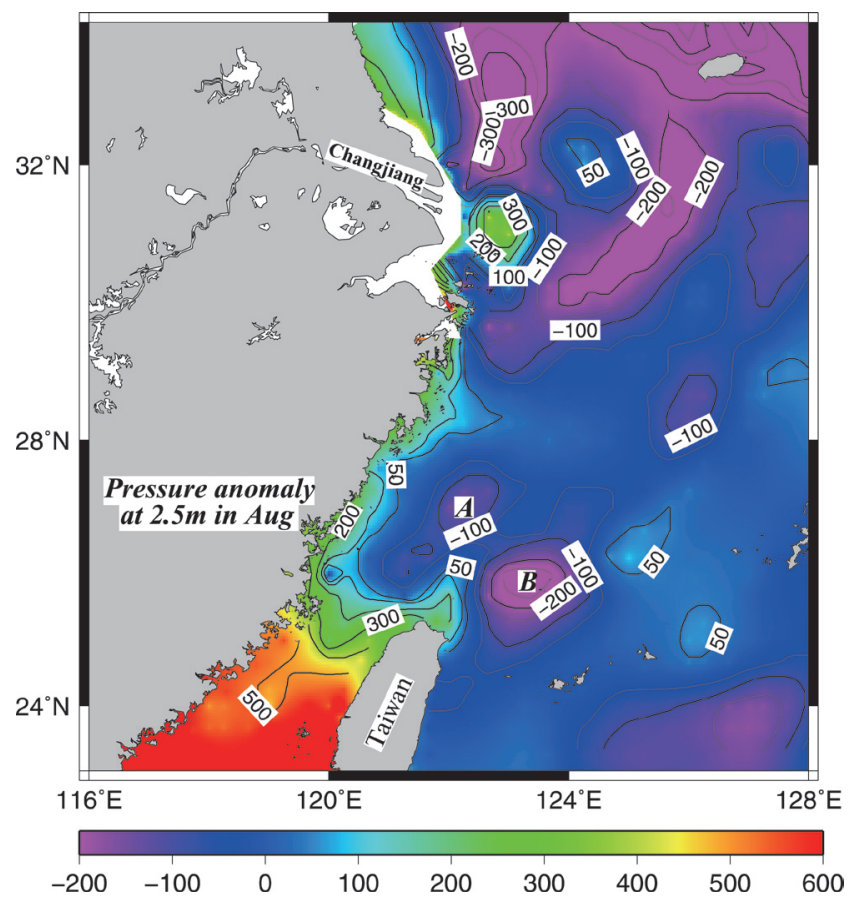

Fig. 12. Tide-induced pressure anomaly (in $\mathrm{Nt} \mathrm{m}^{-2}$ ) off southeast China at $2.5 \mathrm{~m}$ below mean sea level for August. Low pressure anomalies A and B in the southern East China Sea coincide with regions where the Taiwan Warm Current and Kuroshio meander are deflected eastward due to tidal effects.

becomes a mid-shelf high anomaly off northern tip of Taiwan. The U-turn is the well known result of Kelvin wave reflection from the sudden deepening of topography in the lower reaches of the Taiwan Strait (Jan et al. 2002). The inner shelf high could conceivably squeeze the axis of Taiwan Warm Current somewhat eastward (Fig. 11) and produce southward tidal residual flow along southeast coast of China (Fig. 6c). The eastward shift of Taiwan Warm Current, in turn, produces a low pressure anomaly (A) some distance north of Taiwan in Fig. 12. Further, the high pressure anomaly off the northern tip of Taiwan could conceivably shift the on-shelf intrusion of Kuroshio meander off northeast Taiwan eastward (Fig. 11). The eastward shift, in turn, produces the low pressure anomaly (B) off northeast Taiwan in Fig. 12.

When a left-bounded boundary current in the northern hemisphere is, for some reason, deflected seaward, upwelling usually develops to fill part of the void. This occurs in many parts of the ocean, and are too numerous to discuss here. To the south of Japan, the sometimes occurring large meander state of the Kuroshio path often induces upwelling off Shionomisaki (Shoji 1972). Off southeast US, similar upwelling also occurs after the Gulf Stream flows past the socalled Charleston Bump (Xie et al. 2007). Off northeast Taiwan, the seaward (eastward) deflection of the Kuroshio also induces similar upwelling (Wu et al. 2008). In the present case of the Taiwan Warm Current, the sudden loss of lateral confinement provided by Taiwan coast triggers the seaward deflection. Figure 13 illustrates two likely consequences. In Fig. 13a, the seaward deflection induces a cyclonically sheared current on the shoreward side. In Fig. 13b, the seaward deflection is strong enough to induce a cyclonic eddy on the coastal side. Either way, upwelling normally occurs on the coastal side to fill part of the void. The initially low pressure zone caused by the seaward deflection could initiate upwelling. Also, the bottom Ekman transport associated with the partially northward meander current is shoreward and favors upwelling on its shoreward side. The distinction between the two mechanisms may not have practical importance because both contribute to upwelling on the coastal side. Conceivably, more drastic seaward deflections (such as that enhanced by tides) should induce stronger upwelling and stronger cyclonic current shear on the shoreward side.

Off southeast China, the summer upwelling (Figs. 10a,c), the southward tidal residual flow (Fig. 6c) and the seaward deflection of Taiwan Warm Current (Fig. 11) appear to be a trinity; none seems able to survive in the absence of others. Local winds do not seem relevant, as summer climatology winds used to drive the model are either faintly or not even upwelling favorable off southeast China. If the Taiwan Warm Current is forced to deflect at lower latitude, in the present example by tides, the coastal upwelling and southward tidal residual current off southeast China grow concurrently. In winter, under the strong northeast monsoon, the Taiwan Warm Current becomes weak to nonexistent and the coastal upwelling off southeast China disappears. In consequence, none of the three components survive. However, if we terminate the northeast monsoon in winter for a few weeks or longer, it can be verified that the three (coastal upwelling, southward tidal residual flow and seaward deflection of Taiwan Warm Current off southeast China) reappear together. Further, tides will strengthen the three processes as in the summer case. An illustration of the wind relaxation experiments is not included here.

\section{OBSERVATIONS OFF SOUTHEAST CHINA}

Summer upwelling off southeast China has received little attention. Since the construction of Three-Gorge Dam, a long-term biogeochemical monitoring program to track the inter-annual variation of the productivity of the East China Sea has been conducted. Hydrographic measurements have been included as a core monitoring program. Results from the long-term monitoring lend further support to the existence of winter China Coastal Current from the Changjiang southward. These observations are inadequate to delineate tidal effects. Nevertheless, summer upwelling off southeast China can be better understood. We use results from the winter 2008 (from Ocean Research I cruise 855) and summer 2007 (from Ocean Research I cruise 836) to facilitate discussion. The winter cruise was particularly rare because of treacherous sea conditions under the north-northeast monsoon. 
Figure 14 shows ship tracks and stations for the winter cruise (a) and summer cruise (b). Winter stations are understandably fewer than summer stations. On average, the time lag between CTD-Biogeochemical stations was about 6 hours in winter and 7 hours in summer. Weather permitting, the measurement depths were maintained at 2,10,25, $50,75,100,125,150,175,200,250$, and $300 \mathrm{~m}$ as much as possible. It took about 9 days (January $1-9,2008$ ) and 11 days (July $1-11,2007)$ to complete the winter and summer cruises, respectively. Tidal aliasing among stations was a concern. However, prevalent sea conditions as revealed below by the quasi-synoptic satellite images of sea surface temperature (SST) and sea surface height anomaly (SSHA) far outweighed tidal aliasing.

Figure 15a shows a time series of 3-hourly wind sticks at Pengjiayu Islet $\left(122^{\circ} 04^{\prime} 17^{\prime}\right.$ 'E, $25^{\circ} 37^{\prime} 46^{\prime}$ 'N) shortly before, during and after the winter observation period, followed below by satellite-derived SST averaged over the winter observation period (Fig. 15b), observation-derived temperature (Fig. 15c), salinity (Fig. 15d) and density (Fig. 15e) at $3 \mathrm{~m}$ depth. SST is retrieved from the infrared bands of Moderate Resolution Imaging Spectroradiometer (MODIS). In-situ observations, delineated by a window in the wind time series (Fig. 15a), were conducted in a relatively quiescent period between two episodes of northwesterly winds. The SST (Fig. 15b) shows a coastal band of cold water stretching southward from the Changjiang mouth. This is the well-known China Coastal Current driven by the winter north-northeast (and hence downwelling-favorable) monsoon. The downwelling-favorable wind is expected to not only bring surface shelf waters shoreward but also produce a southward coastal jet that carries northern, colder water southward. Temperature (Fig. 15c) and salinity (Fig. 15d) increase seaward over the East China Sea shelf, indicative of the shoreward Kuroshio intrusion in winter. Combining temperature and salinity together, the water density (Fig. 15e) is only slightly buoyant along China coastline. Hydrographic data at other depths showed similar coastal anomalies and are not shown here.

Figure 16 shows corresponding results in summer 2007. The time series of 3-hourly wind sticks (Fig. 16a) covers the observation period delineated by a time window, in which winds were mostly about $6 \mathrm{~m} \mathrm{~s}^{-1}$ southerly. Recall that the spatial-temporal averaged climatology winds in similar summer setting (August) are not even upwelling-favorable (Fig. 1b). The satellite-derived SST (Fig. 16b) shows a coastal band of cold anomalies along China south of $30^{\circ} \mathrm{N}$. The observed wind stress at this time, about $0.56 \mathrm{dyne} \mathrm{cm}^{-2}$, was too weak to drive a strong coastal upwelling. On the other hand, the climatology wind stress used to drive the circulation model at

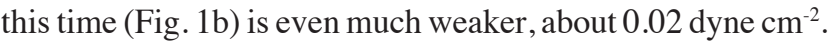
Instead, our numerical results suggest that tides and seaward deflection of Taiwan Warm Current drove the summer upwelling off southeast China (Figs. 10a and c). The temperature

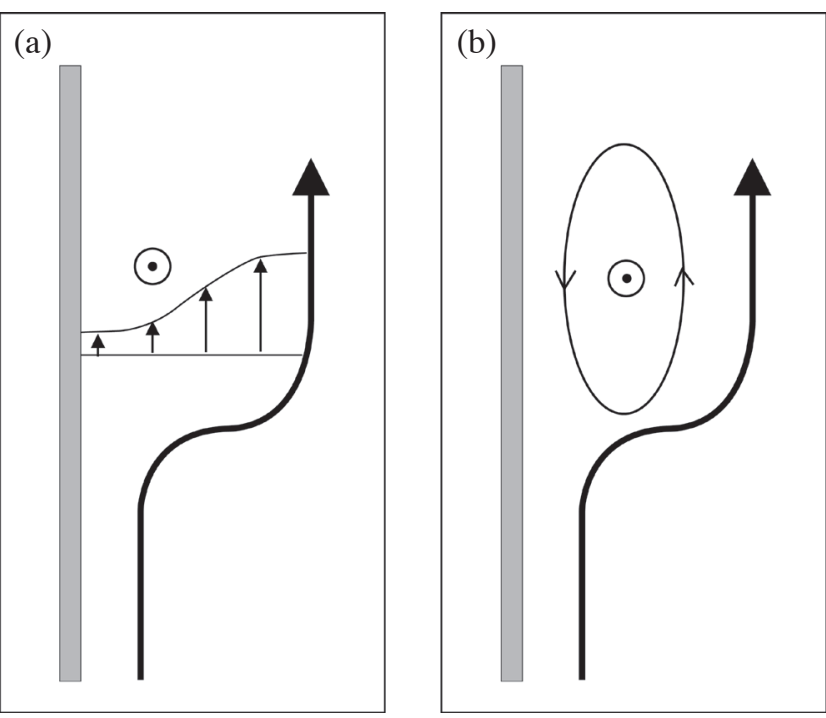

Fig. 13. Seaward deflection of a left-bounded boundary current in the northern hemisphere, consequent upwelling and (a) cyclonic current shear or (b) cyclonic eddy on the shoreward side.

(a)

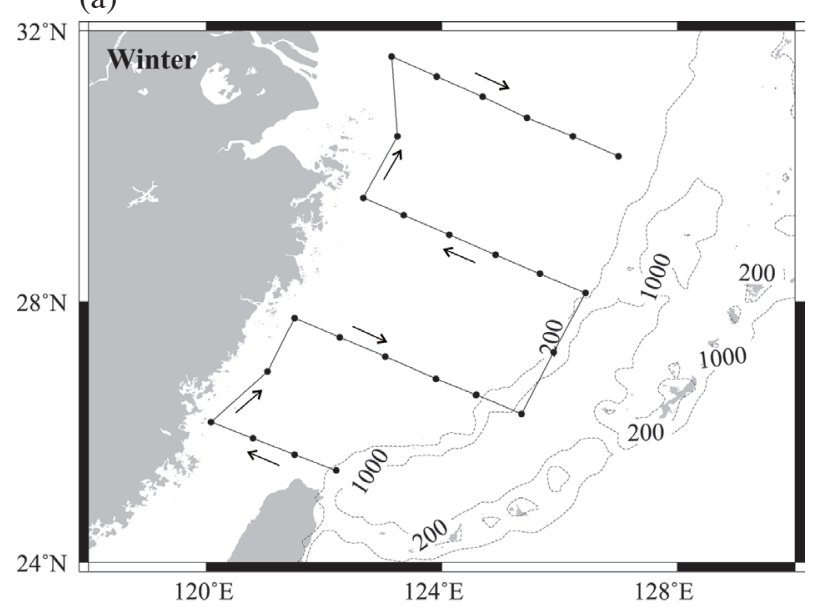

(b)

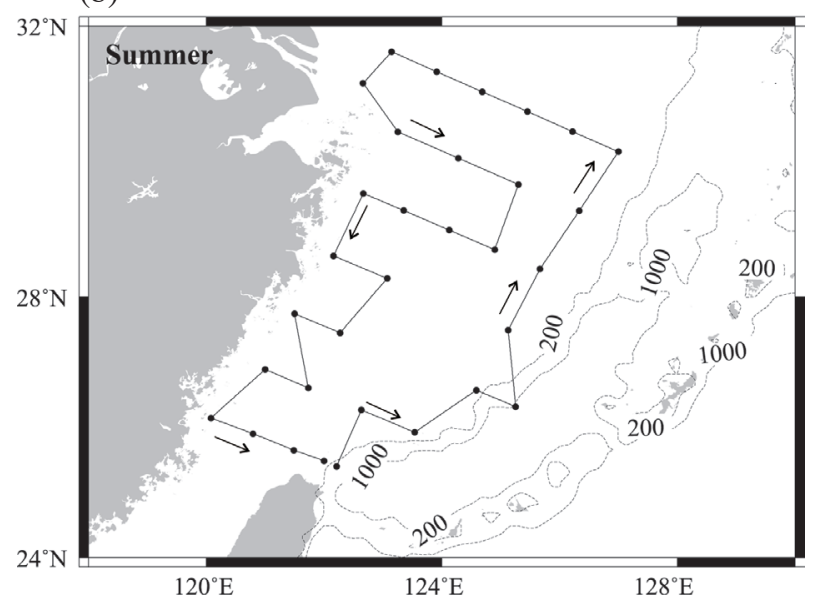

Fig. 14. Ship tracks of CTD stations in (a) winter 2008 and (b) summer 2007 visited by Ocean Research I of Taiwan (OR1). Dashed isobaths are in meters. Time lags between stations are about 7 hours in summer and 6 hours in winter. 

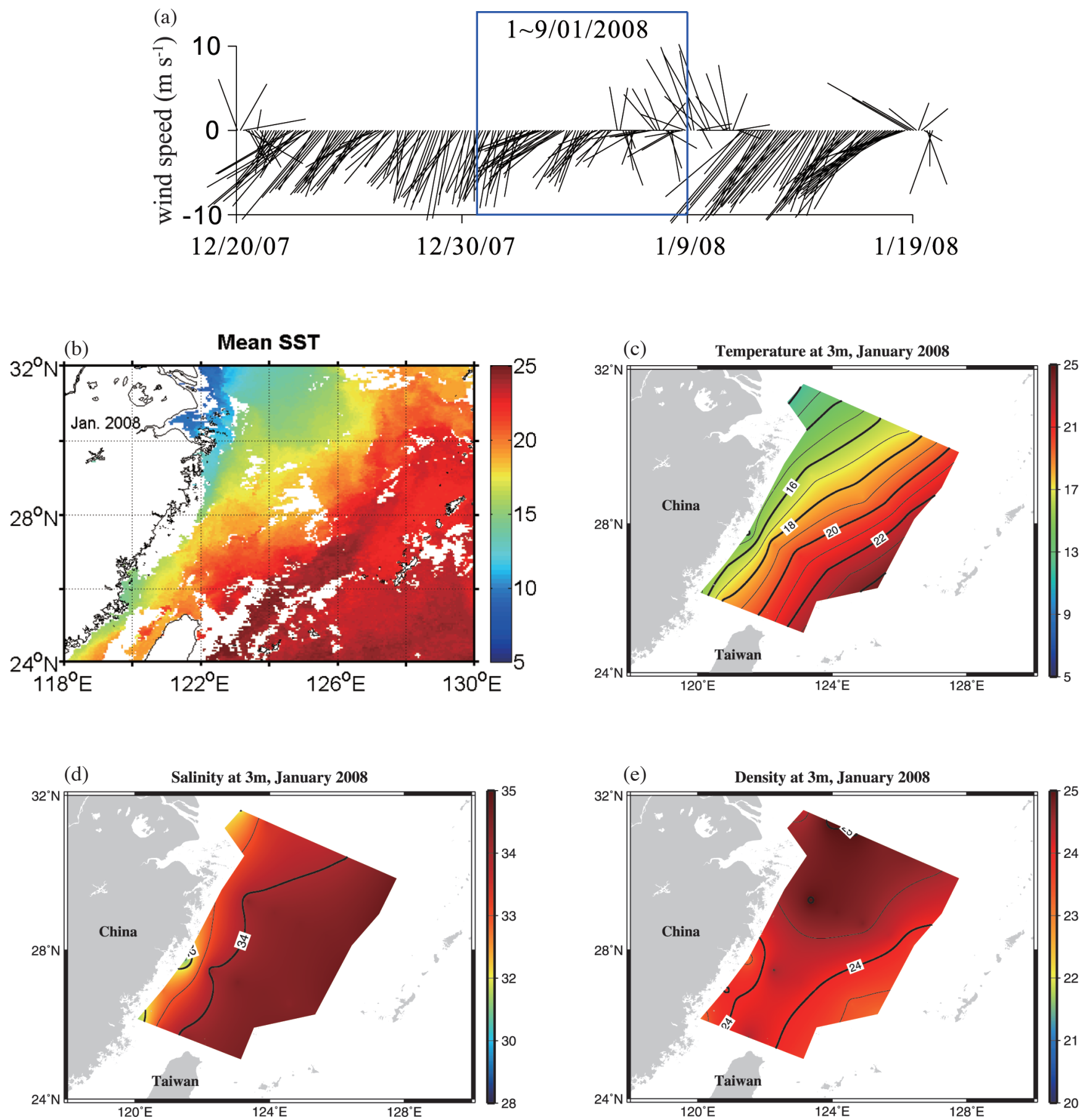

Fig. 15. (a) Wind time series before, during and after the winter observation period (January 1 - 9, 2008) derived from Pengjiayu Islet meteorological station. (b) Satellite-derived SST (in ${ }^{\circ} \mathrm{C}$ ) averaged over the observation period. Temperature in ${ }^{\circ} \mathrm{C}(\mathrm{c})$, salinity in psu (d) and density in $\sigma_{\mathrm{t}}\left(\mathrm{kg} \mathrm{m}^{-3}\right.$ ) (e) at $3 \mathrm{~m}$ depth below sea level. 

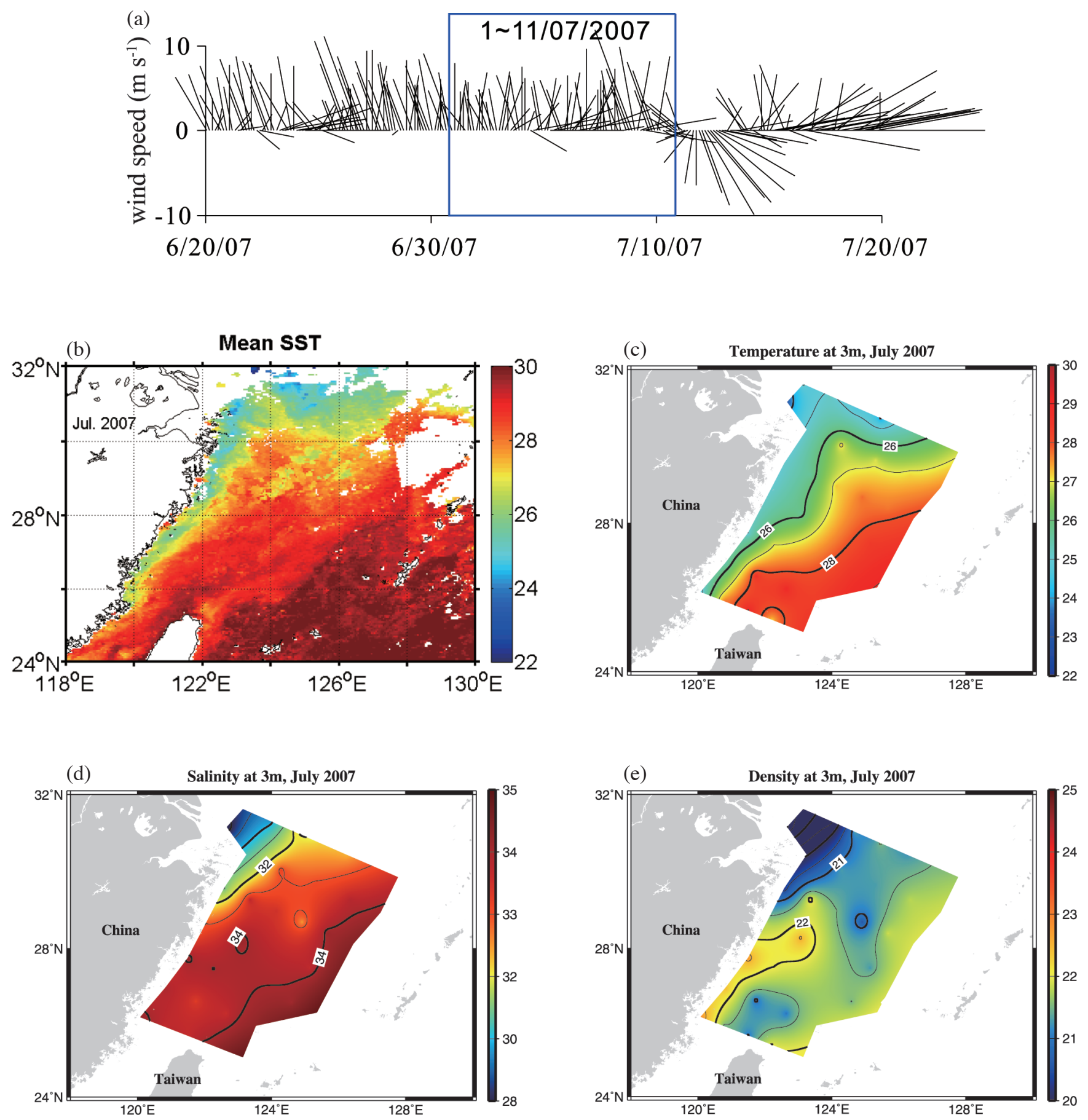

Fig. 16. Same as Fig. 15 except for the summer observation period (July 1 - 11, 2007). 
at $3 \mathrm{~m}$ (Fig. 16c) increases only mildly seaward over the East China Sea shelf in summer, indicative of reduced Kuroshio intrusion. The salinity field at $3 \mathrm{~m}$ (Fig. 16d) shows Changjiang diluted water only in the vicinity of Changjiang mouth, unable to expand southward as one would expect under the summer southwest monsoon. Combining temperature and salinity, density field at $3 \mathrm{~m}$ (Fig. 16e) shows a tongue of upwelled denser water stretching from China coast around $28^{\circ} \mathrm{N}$ northeastward. The loosely trapped band of cold water along the coast deviates considerably from the traditional wind-driven coastal upwelling scenario. As we will illustrate in Fig. 17, the empirically estimated transport in the Taiwan Strait was reasonably strong and northward at this time. The seaward deflection of Taiwan Warm Current coming out of the Taiwan Strait in summer is expected to occur in conjunction with this upwelling. Hydrographic data at other depths show similar anomalies and will not be illustrated.

The mostly northward transport of the Taiwan Warm Current is known to increase in summer but decrease in winter after the arrival of the northeast monsoon. To quantify fur- ther, $\mathrm{Wu}$ and Hsin (2005) related the strait transport ( $T$ in $\mathrm{Sv}$ ) to the hourly averaged along-strait wind stress $\left(\tau\right.$ in dyne $\left.\mathrm{cm}^{-2}\right)$ as $T=1.06 \tau+1.99$, where both $T$ and $\tau$ are positive northward. Using the nearby Pengjiayu Islet hourly winds, we calculated the corresponding wind stress following Yelland and Taylor (1996). Figure 17 shows hourly Taiwan Strait transport (in black) and time-smoothed transport (in red) derived from wind stress (in blue) measured at Pengjiayu Islet meteorological station for (a) winter 2008 and (b) summer 2007. Windows in the two panels delineate the two seagoing observation periods. Despite the north-northeast monsoon, the Taiwan Strait transport is mostly northward but much reduced in winter. In summer, The Taiwan Strait transport increases markedly with the disappearance of the northeast monsoon. This is the time of summer upwelling off southeast China.

Sea surface height anomalies (SSHA) can also be used to further distinguish summer and winter cold anomalies along the southeast coast of China apart. SSHA is derived from Archiving, Validation and Interpretation of Satellite Oceanographic data (AVISO), which is a delayed time
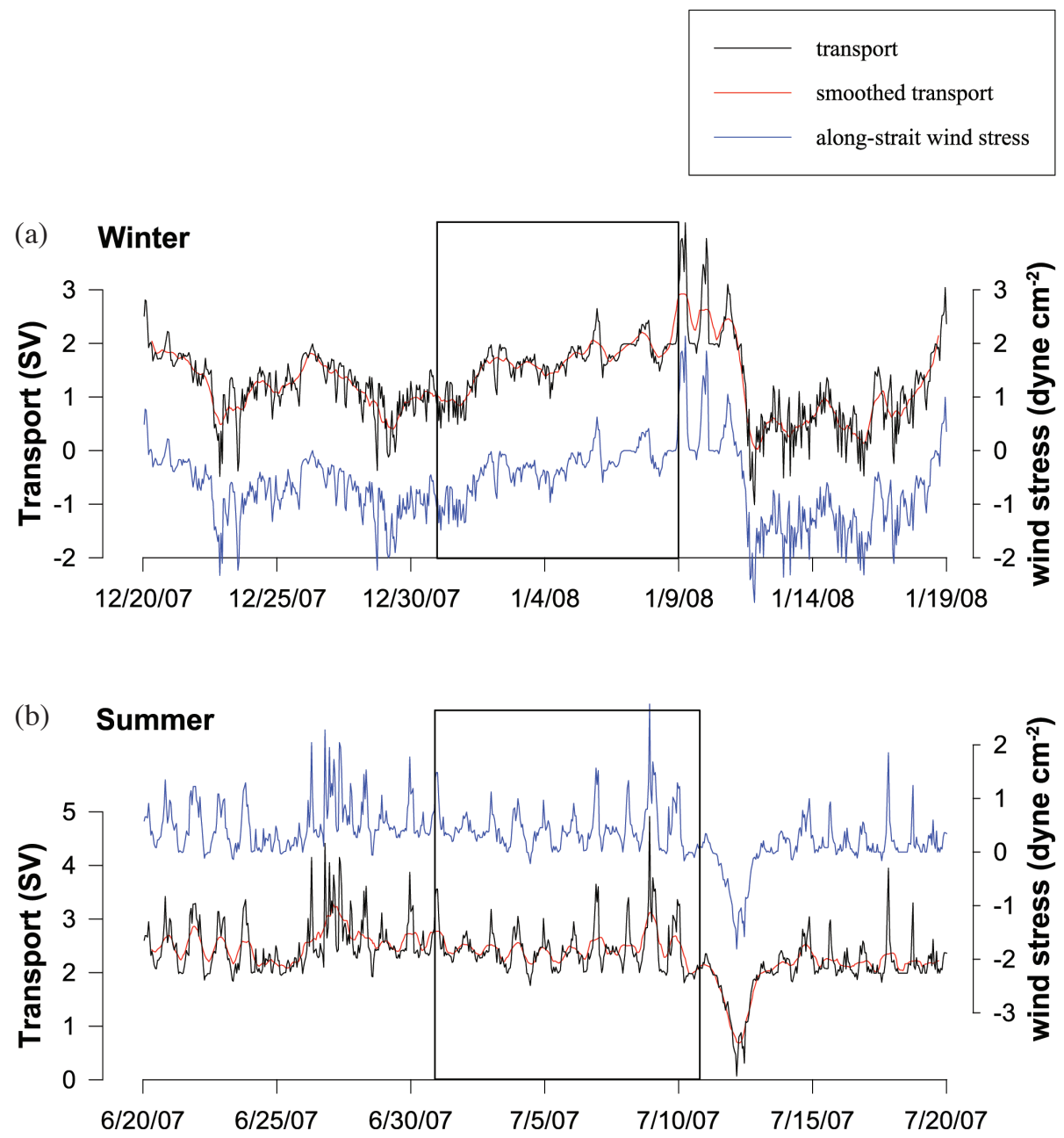

Fig. 17. Empirical estimates of volume transport in the Taiwan Strait based on hourly wind stress derived from Pengjiayu Islet station in (a) winter 2008 and (b) summer 2007. Positive transport is northward. Time averaging in red was done with a moving window 15 hours wide. 
assimilation of processed Jason-1, Jason-2, T/P, Envisat, GFO, ERS1/2 and even Geosat data. SSHA are computed as the averaged deviation of sea level height during our winter and summer observation periods from the all time mean (mean sea surface) of the same product. Figure 18a shows SSHA averaged over the winter observation period in 2008; high sea level anomaly accompanied the cold water off southeast China (Fig. 15b), suggesting a downwelling coastal jet that carries northern, colder water southward. In summer (Fig. 18b), low sea level anomalies occurred concurrently with cold water appearance off southeast China (Fig. 16b). This is a telling feature of near-shore upwelling.

\section{CONCLUSIONS}

Building on a previously validated circulation model driven by monthly climatology (Lee and Chao 2003), we have incorporated tides in the model to examine their effects on Changjiang plume dispersal and the mean circulation mostly off southeast China. With or without tides, the model captures major circulation features such as the Kuroshio, the Taiwan Warm Current and the China Coastal

(a)

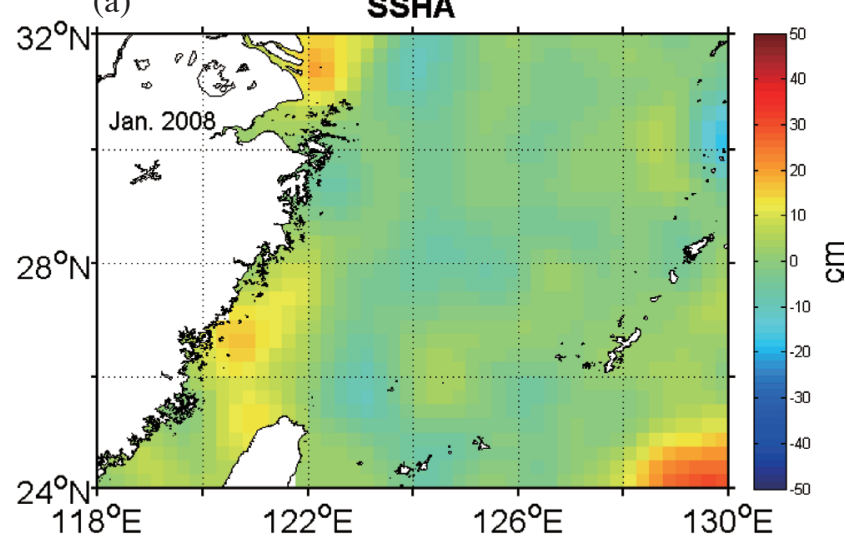

(b)

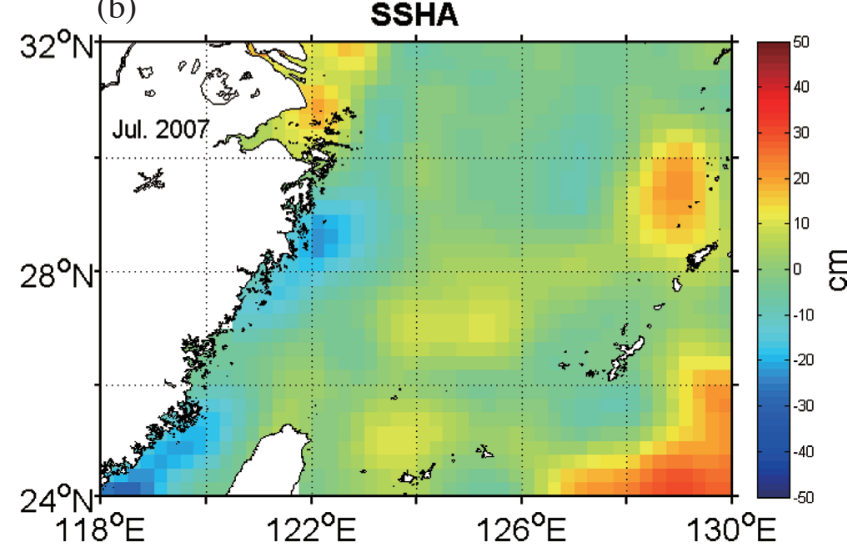

Fig. 18. Sea surface height anomalies (SSHA) averaged over observation periods in (a) winter (January 1 - 9) 2008 and (b) summer (July 1 - 11) 2007.
Current reasonably well. Tidal currents energize the shelf circulation further. Following SSS, we have examined the Changjiang plume and tracked the dispersal with and without tides. In summer, tidal currents consistently displace the plume somewhat to the south and therefore bring the results from the model closer to observations. This occurs with the development of southward residual tidal flow off southeast China. In winter, tidal currents reduce the plume concentration seaward, north and south of Changjiang mouth.

The summer offshore detachment of Changjiang plume is also noteworthy. Tides produce a residual anticyclone off Changjiang mouth with a strong seaward flow in the north and a weak return flow to the south. If tides are sufficiently strong during spring tide, the predominant seaward tidal residual flow could conceivably enhance the plume's ability to detach seaward. As discussed in Moon et al. (2010), Wu et al. (2011) and the present work, southerly winds also enhance the summer plume detachment.

In the East China Sea, the south-southwest monsoon is too weak to stand out in summer. Under this setting, tides suppress the northward expansion of Taiwan Warm Current, enhance near-shore upwelling off southeast China and produce the southward tidal residual flow off southeast China. The three phenomena appear to be inseparable; each could not survive without others. In winter, the north-northeast monsoon dominates, eliminating the three tide-enhanced processes altogether. However, if the winter north-northeast monsoon is allowed to relax sufficiently long, the trinity reappears together. In-situ observations and satellite images help improve our understanding of summer upwelling and winter appearance of the China Coastal Current.

Acknowledgments We are grateful for the kind help of C. K. Hu (TORI, Taiwan). HJL was sponsored by the National Science Council (Taiwan) under grant NSC-99-2611-M-019008. SYC was supported by the Office of Naval Research (US) under grant N00014-09-1-0623. KKL was supported by the National Science Council (Taiwan) under grant NSC-1012611-M-008-004. SJH was sponsored by the National Science Council (Taiwan) under grant NSC-98-2611-M-019-016MY3. GCG was sponsored by the National Science Council (Taiwan) under grant NSC-101-2611-M-019-007-MY3 .

\section{REFERENCES}

Chao, S. Y., 1990: Tidal modulation of estuarine plumes. J. Phys. Oceanogr., 20, 1115-1123, doi: 10.1175/15200485(1990)020<1115:TMOEP>2.0.CO;2. [Link]

Chen, D. X., 1992: Marine Atlas of Bohai Sea, Yellow Sea, East China Sea, Hydrology, China Ocean Press, Beijing, $524 \mathrm{pp}$.

Dean, R. G. and R. A. Dalrymple, 1984: Water Wave Mechanics for Engineers and Scientists, Advanced Series on Ocean Engineering, vol. 2, Prentice-Hall, 353 pp. 
Foreman, M. G. G. and R. F. Henry, 1979: Tidal Analysis Based on High and Low Water Observations, Institute of Ocean Sciences, Patricia Bay, Sidney, British Columbia, Pacific Marine Science Report, Canada, 79-15.

Guo, X. and T. Yanagi, 1998: Three-dimensional structure of tidal current in the East China Sea and the Yellow Sea. J. Oceanogr., 54, 651-668, doi: 10.1007/ BF02823285. [Link]

He, Y. and W. B. White, 1987: Interannual variability of the Kuroshio frontal structure along its western boundary in the North Pacific Ocean associated with the 1982 ENSO event. J. Phys. Oceanogr., 17, 1494-1506, doi: 10.1175/1520-0485(1987)017<1494:IVOTKF>2.0. CO;2. [Link]

Hellerman, S. and M. Rosenstein, 1983: Normal monthly wind stress over the world ocean with error estimates. J.Phys. Oceanogr., 13, 1093-1104, doi: 10.1175/15200485(1983)013<1093:NMWSOT>2.0.CO;2. [Link]

Hu, C. K., C. T. Chiu, S. H. Chen, J. Y. Kuo, S. Jan, and Y. H. Tseng, 2010: Numerical simulation of barotropic tides around Taiwan. Terr. Atmos. Ocean. Sci., 21, 7184, doi: 10.3319/TAO.2009.05.25.02(IWNOP). [Link]

Jan, S., C. S. Chern, and J. Wang, 2002: Transition of tidal waves from the East to South China Seas over the Taiwan Strait: Influence of the abrupt step in the topography. J. Oceanogr., 58, 837-850, doi: 10.1023/ A:1022827330693. [Link]

Lee, S.H. and R.C. Beardsley, 1999: Influence of stratification on residual tidal currents in the Yellow Sea. J. Geophys. Res., 104, 15679-15701, doi: 10.1029/1999JC900108. [Link]

Lee, H. J. and S. Y. Chao, 2003: A climatological description of circulation in and around the East China Sea. Deep-Sea Res. Part II-Top. Stud. Oceanogr., 50, 10651084, doi: 10.1016/S0967-0645(03)00010-9. [Link]

Lefevre, F., C. Le Provost, and F. H. Lyard, 2000: How can we improve a global ocean tide model at a regional scale? A test on the Yellow Sea and the East China Sea. J. Geophys. Res., 105, 8707-8725, doi: 10.1029/1999JC900281. [Link]

Levitus, S. and T. P. Boyer, 1994: World Ocean Atlas 1994 Volume 4, NOAA Atlas NESDIS 4, U. S. Department of Commerce, Washington, D. C.. Available at http:// ingrid.ldgo.columbia.edu/SOURCES/.LEVITUS94/.

Li, M. and Z. Rong, 2012: Effects of tides on freshwater and volume transports in the Changjiang River plume.J.Geophys. Res., 117, C06027, doi: 10.1029/2011JC007716. [Link]

Lie, H. J., C. H. Cho, J. H. Lee, and S. Lee, 2003: Structure and eastward extension of the Changjiang River plume in the East China Sea. J. Geophys. Res., 108, doi: 10.1029/2001JC001194. [Link]

Liu, K. K., S. Seitzinger, E. Mayorga, J. Harrison, and V. Ittekkot, 2008: Fluxes of nutrients and selected organic pollutants carried by rivers. In: Urban, E. R., B. Sundby, P. Malanotte-Rizzoli, and J. M. Melillo, (Eds.), Watersheds, Bays, and Bounded Seas: The Science and Management of Semi-Enclosed Marine Systems, Scientific Committee on Problems of the Environment (SCOPE) Series (Book 70), Island Press, Washington D. C., 141-167.

Moon, J. H., N. Hirose, J. H. Yoon, and I. C. Pang, 2010: Offshore detachment process of the lowsalinity water around Changjiang bank in the East China Sea. J. Phys. Oceanogr., 40, 1035-1053, doi: 10.1175/2010JPO4167.1. [Link]

Nitani, H., 1972: Beginning of the Kuroshio. In: Stommel, H. and K. Yoshida (Eds.), Kuroshio: Physical Aspects of the Japan Current , University of Washington Press, 129-163.

Pacanowski, R. C. and S. G. H. Philander, 1981: Parameterization of vertical mixing in numerical models of tropical ocean. J. Phys. Oceanogr., 11, 1443-1451, doi: 10.1175/1520-0485(1981)011<1443:POVMIN>2.0. CO;2. [Link]

Pugh, D. T., 1987: Tides, Surges, and Mean Sea-Level, John Wiley and Sons Ltd., New York, 472 pp.

Rong, Z. and M. Li, 2012: Tidal effects on the bulge region of Changjiang River plume. Estuar. Coast. Shelf Sci., 97, 149-160, doi: 10.1016/j.ecss.2011.11.035. [Link]

Sarmiento, J. L. and K. Bryan, 1982: An ocean transport model for the North Atlantic. J. Geophys. Res., 87, 394-408, doi: 10.1029/JC087iC01 p00394. [Link]

Shoji, D., 1972: Time variation of the Kuroshio south of Japan. In: Stommel, H. and K. Yoshida (Eds.), Kuroshio: Physical Aspects of the Japan Current, University of Washington Press, 217-234.

Wu, C. R. and Y. C. Hsin, 2005: Volume transport through the Taiwan Strait: A numerical study. Terr. Atmos. Ocean. Sci., 16, 377-391.

Wu, C. R., S. Y. Chao, and C. Hsu, 2007: Transient, seasonal and interannual variability of the Taiwan Strait current. J. Oceanogr., 63, 821-833, doi: 10.1007/s10872007-0070-1. [Link]

Wu, C. R., H. F. Lu, and S. Y. Chao, 2008: A numerical study on the formation of upwelling off northeast Taiwan. J. Geophys. Res., 113, C08025, doi: 10.1029/2007JC004697. [Link]

Wu, H., J. Zhu, J. Shen, and H. Wang, 2011: Tidal modulation on the Changjiang River plume in summer. J. Geophys. Res., 116, C08017, doi: 10.1029/2011JC007209. [Link]

Xie, L., X. Liu, and L. J. Pietrafesa, 2007: Effect of bathymetric curvature on Gulf Stream instability in the vicinity of the Charleston Bump. J. Phys. Oceanogr., 37, 452-475, doi: 10.1175/JPO2995.1. [Link]

Yanagi, T., A. Morimoto, and K. Ichikawa, 1997: Co-tidal and co-range charts for the East China Sea and the 
Yellow Sea derived from satellite altimetric data. $J$. Oceanogr., 53, 303-309.

Yelland,M.andP.K.Taylor,1996:Wind stress measurements from the open ocean. J. Phys. Oceanogr., 26, 541-558, doi: 10.1175/1520-0485(1996)026<0541:WSMFTO> 2.0.CO;2. [Link] 